\title{
Material and component investigations on a Ti-6-4 fitting element
}

\author{
Wen Tan $^{1, a}$ Michael Stoschka ${ }^{2}$, Martin RiedleR $^{3}$, Wilfried Eichlseder ${ }^{1,2}$ \\ Fernando Romagnoli ${ }^{4}$ and Vinícius Rondon ${ }^{4}$ \\ 1 Christian Doppler Laboratory for Fatigue Analysis, Franz-Josef-Str. 18, 8700 Leoben, Austria \\ 2 Chair of Mechanical Engineering, Montanuniversität Leoben, Franz-Josef-Str. 18, 8700 Leoben, Austria \\ 3 Böhler Schmiedetechnik GmbH \& Co KG, Mariazeller Strasse 25, 8605 Kapfenberg, Austria \\ 4 EMBRAER Brasileira de Aeronautica S.A, Av. Brigadeiro Faria Lima 2170, São José dos Campos, Brasil
}

Received 24 August 2010, Accepted 15 June 2011

\begin{abstract}
An improvement in the life time calculation is aspired by the characterisation of the life time behaviour of a typically lightweight aircraft titanium alloy by describing the microstructure. Therefore, extensive research on a Ti-6-4 fitting element has been carried out. In addition to static tensile tests, rotating bending tests and fracture mechanical tests, component tests with constant and variable load were performed. Simultaneously, the microstructures of the specimens and tested components are extensively analysed at several points including the lug area, as well as, the specimen's microstructure taken out of the lower link fitting. A common consideration of life time results as well as results of the microstructure in the life time calculation shows the possibilities for more precise life time estimation.
\end{abstract}

Key words: High cycle fatigue / fracture mechanics / life prediction / titanium alloys / microstructures

\section{Introduction}

The methods of life time calculation of real components in the development process become more and more important due to reduction in cost and time with simultaneous improvement in reliability. Nowadays, it is not enough to just consider the different loading cases of the final component but rather it is also necessary to study the full production process to determine the critical life time of the component. Ti-6-4 is a typical material used in aircraft components which meets the necessary requirements such as fatigue strength, lightweight and reliability $[1,2]$. In this study two different production processes are compared. The classical way is to manufacture highly stressed air craft components by milling the parts out of blocks. A more recent technique to manufacture this component is through forging. The beneficial aspects of forging components are cutting as less fibre material as possible, cost efficiency and better process control. Therefore, the basic form is obtained by different forging processes as well as different heat treatment. The subsequent heat treatment of the semi-finished product influences the behaviour of the final component as well. In this study, the two different production processes viz. forging and machining of a plate, referred to as hog-out, are considered.

\footnotetext{
${ }^{a}$ Corresponding author: wen.tan@unileoben.ac.at
}

\section{Nomenclature}

\begin{tabular}{|lll|}
\hline$\chi$ & stress gradient & {$[-]$} \\
$\Delta K$ & cyclic stress intensity & {$\left[\mathrm{MPa}^{1 / 2} \mathrm{~m}^{-2}\right.$} \\
$\mathrm{d} a / \mathrm{d} N$ & crack growth rate & {$\left[\mathrm{mm}_{\mathrm{c}} \mathrm{cycl}^{-1}\right]$} \\
$\varepsilon$ & strain & {$[\%]$} \\
$k$ & slope of S/N-curve & {$[-]$} \\
$K_{t}$ & stress concentration factor & {$[-]$} \\
$m$ & slope of the Paris - line $\left[\mathrm{N} . \mathrm{mm}^{-2}\right]$ & \\
$N$ & number of load cycles & {$[-]$} \\
$P s$ & survival probability & {$[-]$} \\
$R$ & stress ratio & {$[-]$} \\
$S_{\mathrm{a}, \mathrm{bu}}$ & normalized stress amplitude & {$\left[\mathrm{N} \cdot \mathrm{mm}^{2}\right]$} \\
$S_{\mathrm{max}}$ & maximal stress amplitude & {$\left[\mathrm{N} \cdot \mathrm{mm}^{2}\right]$} \\
$T h$ & threshold of stress intensity & {$\left[\mathrm{MPa}^{1 / 2}\right]$} \\
\hline
\end{tabular}

The former yielded a bi-modal, and the latter a lamellar microstructure. In spite of differences in the production processes, the geometry of the tested components was identical and in total, six components from each set were tested. The considered component for this investigation is a custom made fitting which is very typical for every airplane, see Figure 1. The lug here is in both instances machined and an Inconel bushing is glued with a minute play. Once the mechanisms are clarified, the knowledge 


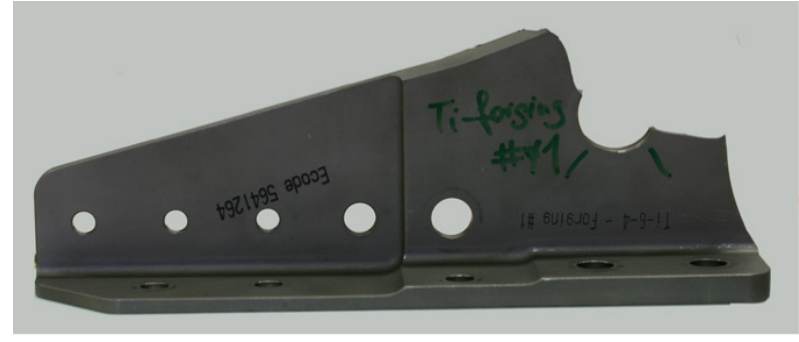

Fig. 1. Fitting element.

can be used for a more improved design of similar fittings for airplanes in service.

For a computational approach of the life time of a component, relevant material data are necessary. Therefore a wide range of tests have been carried out. A basic method of how to describe the component behaviour is by using material tests out of the component. The results of constant and variable amplitude tests of the real component were compared to show similarities between material- and components tests. In our investigation, at first the components tests were carried out and three different specimens were generated directly out of the tested component, one each for tensile test, rotating bending test and fracture mechanic test. The aim of the specimen tests is to obtain relevant material data for further life time calculation with FEMFAT. Results from ABAQUS simulation of the component test revealed that the regions from where the specimens were obtained experienced only a tiny amount of tensile loading even at maximum load, see Figure 2. Hence no effect of the preceding components test is assumed on the results of the specimen test.

Formation of different microstructures within the component can be found due to the production process. In addition to the fatigue behaviour results, the microstructure from the two manufacturing processes was also considered. As shown below, the life time values obtained are affected by the microstructure.

\section{Testing}

The fatigue tests on the components were carried out with a stress ratio $R=0.1$. The component tests were carried out on a servo-hydraulic test rig of Instron, with a nominal force of $250 \mathrm{kN}$, see Figure 3, using an Instron FastTrack control system. The clamping was done via specially manufactured devices to elucidate conditions in a real component. The components were tested under force control.

The specimen generated from this tested component were further test subjected to pure tensile test, rotating bending test and fracture mechanical test. The tensile tests on the specimen were carried out on a servohydraulic test rig from Instron with a nominal force of 100 kN, using an Instron FastTrack control system. The specimens were clamped using mechanical clamping grips. If the specimen lasted for the entire twenty million cycles,

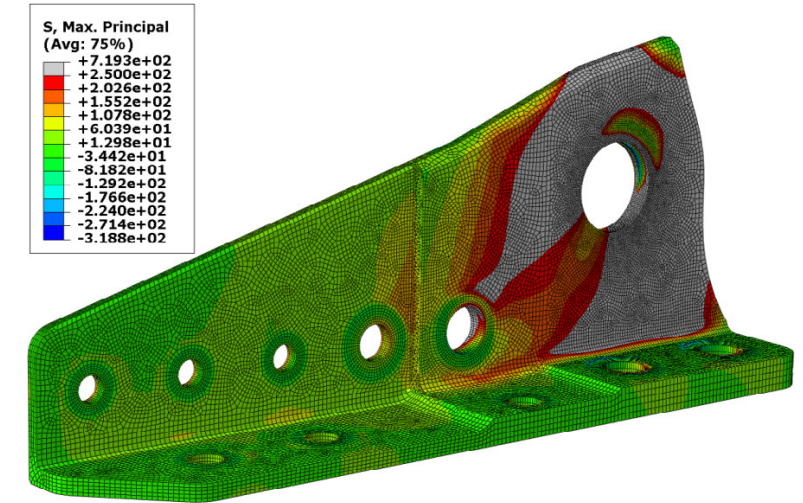

Fig. 2. Max. Principal stress at $118 \mathrm{kN}$ load from FEM simulation.

it was labelled as a run through. The fatigue crack growth tests were carried out using a RUMUL test equipment.

\subsection{Specimen generation}

The specimens used for tensile tests were produced in accordance to DIN 50125 standards. The flat specimens were taken out of the rear, top area of the lower link fittings as shown in Figure 4. The tensile tests were carried out using the specimen geometry as shown in Figure 5. The nominal thickness of the specimen was $4 \mathrm{~mm}$, whereas the flat cross-section surface of the specimen is equivalent to the lower link fitting, which means that no additional machining was needed on these faces.

Rotating bending specimens were manufactured out of the thickest portions of the lower link fitting and due to its geometry, only two positions are favourable, see Figure 6 . The specimen taken out of the middle section near the "bending" edge of the fitting is labelled as "M", which the outer specimen is labelled as " $\mathrm{R}$ ". Tests were carried out following DIN 50113 norm.

The specimen for the fatigue crack growth tests were produced, following the ASTM E647-00 standards, out of the lower link fittings as shown in Figures 7 and 8 . The thickness of the SENB (single-edge notched bending) specimen was $4 \mathrm{~mm}$ and the surface was not mechanical treated.

The necessary notch is machined on the opposite side of the holes, caused by the manufacturing of the lower link fitting. The crack starts on the outer edge of the fitting and grows to the centre.

\section{Results}

The component and specimen tests carried out are clearly described in this chapter. 

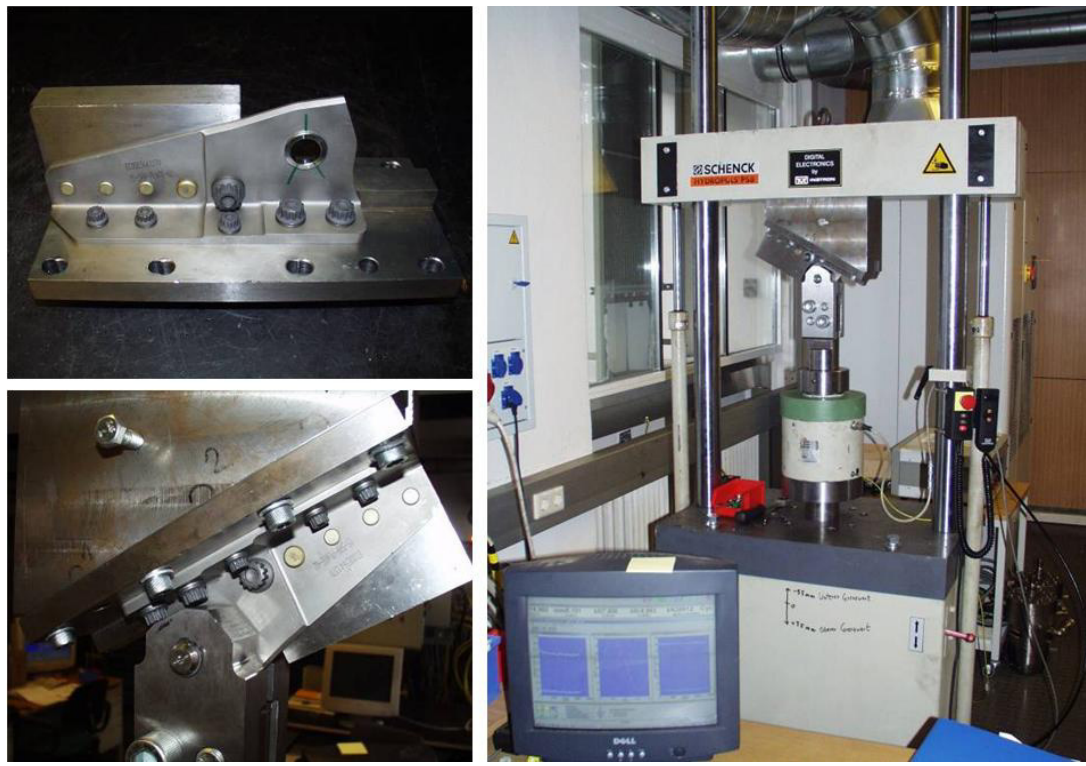

Fig. 3. Test rig and details for component tests.

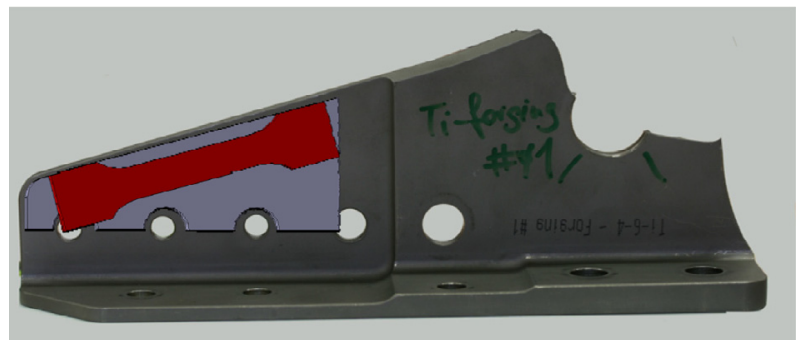

Fig. 4. Specimen position in lower link fitting for tensile tests.

Table 1. Characteristic values for forging lower link fittings.

\begin{tabular}{cccc}
\hline & F5 & F6 & F7 \\
\hline Young's modulus [MPa] & 126214 & 125684 & 113047 \\
Tensile strength [-] & 1.64 & 1.65 & 1.65 \\
Yield strength [-] & 1.52 & 1.51 & 1.52 \\
Uniform strain [\%] & 6.76 & 8.50 & 7.57 \\
Ultimate strain [\%] & 12.27 & 16.62 & 15.92 \\
\hline
\end{tabular}

\subsection{Tensile tests}

A total number of six tensile tests have been done, whereas in each case of manufacturing - both forgings and hog-out - three static tensile tests were carried out.

\subsubsection{Forgings}

All the tensile strength values were close to a particular stress level. Likewise, a uniform strain rate of around six to eight percent was recorded. Table 1 shows the results of the forged lower link fittings of which the stress values are normalized.

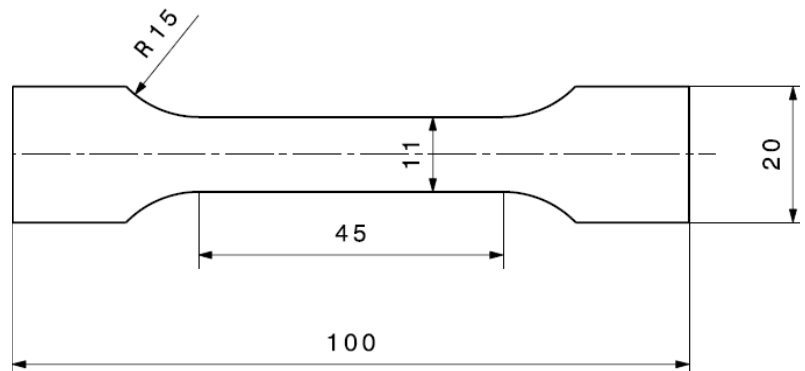

Fig. 5. Tensile test specimen geometry.

Table 2. Characteristic values for hog-out lower link fittings.

\begin{tabular}{cccc}
\hline & P5 & P6 & P7 \\
\hline Young's modulus [MPa] & 110583 & 116293 & 115144 \\
Tensile strength [-] & 1.54 & 1.55 & 1.56 \\
Yield strength [-] & 1.41 & 1.43 & 1.35 \\
Uniform strain [\%] & 8.66 & 9.40 & 8.01 \\
Ultimate strain [\%] & 20.03 & 16.58 & 16.36 \\
\hline
\end{tabular}

\subsubsection{Hog-out}

The tensile tests carried out on the specimen from the hog-out lower link fittings showed a similar behaviour of the tensile strength, which are lower than that for the specimen of forged lower link fitting. The summary of the results was tabulated as shown below.

The hog-out specimens show a higher ductility than the forged ones. The overall scatter observed in the results of the hog-out specimen taken out is distinctly high, supporting the assumption that the forging and shotpeening process increases the overall manufacturing quality of each lower link fitting. Nevertheless, the influence of the fatigue behaviour is more complex due to different influencing factors at the - local complex loaded and part-contacted - lug area of the lower link fitting. 

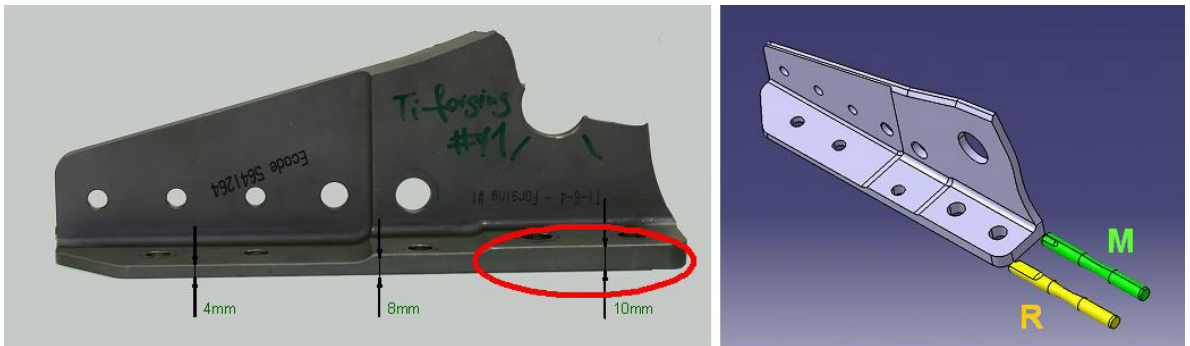

Fig. 6. Possible specimen position in the lower link fitting.

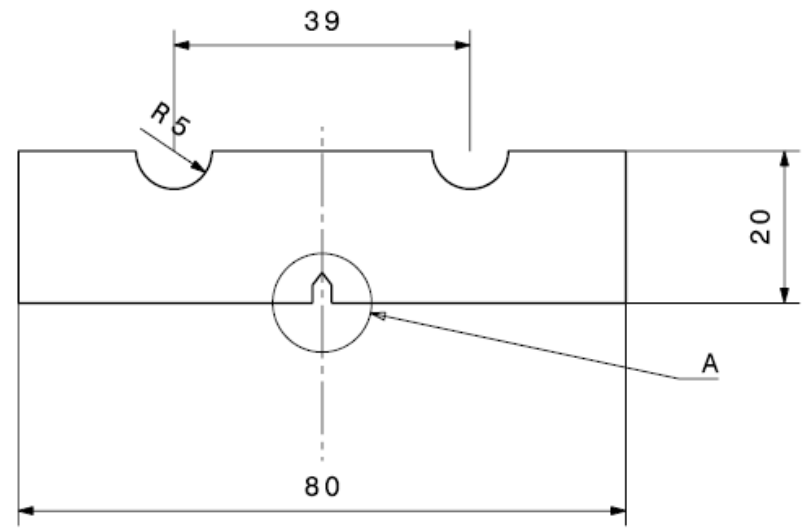

Fig. 7. Specimen geometry for mechanical fracture test.

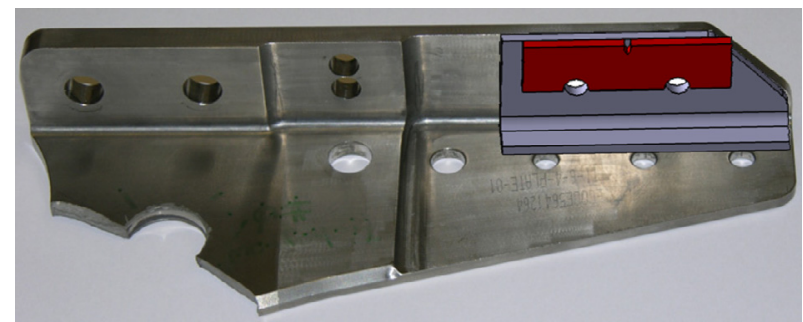

Fig. 8. Fracture mechanical test specimen position in lower link fitting.

\subsection{Rotating bending tests}

The results of the rotating bending tests are summarized and shown in Figure 11. For the forged lower link fitting, two slopes can be determined, while the slope for the hog-out is smaller. The investigated stress values of forging are at least ten percent higher than the hog-out.

Figure 12 shows the detailed S-N curve of the forged lower link fittings. The curve shows that there is no difference between specimens at different positions. The results of the border and middle specimen are similar. A number of specimens could have been used again, if the maximum number of cycles was reached.

For the hog-out, a major difference can be noticed in the results between the middle's and boarder's position can be found, compare the subfigures in Figure 13. The figure on the left shows a summarized S-N curve for the investigated specimen. The specimens produced from near the outer edge show the lowest life time values. Specimens produced from the transition region show an increased

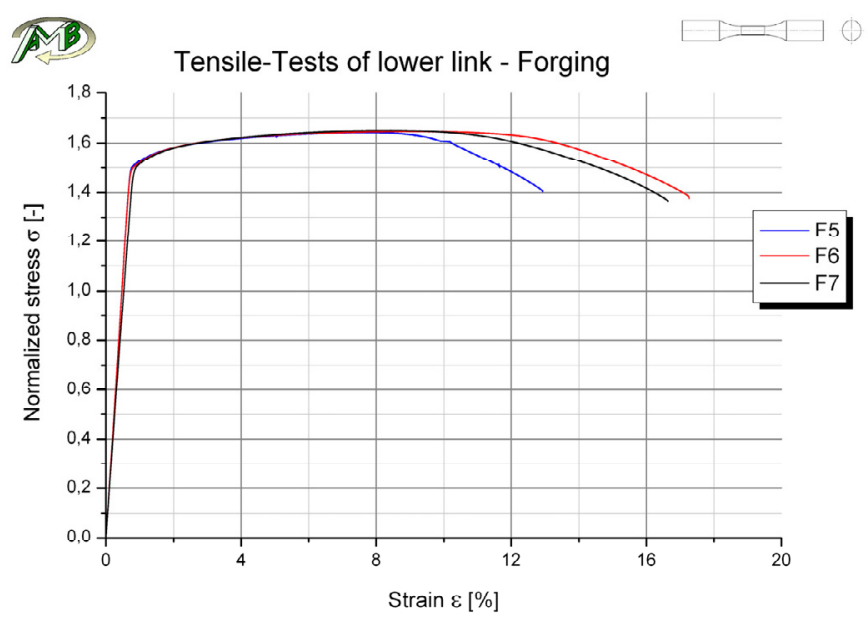

Fig. 9. Tensile test results for the flat specimen out of forged lower link fittings.

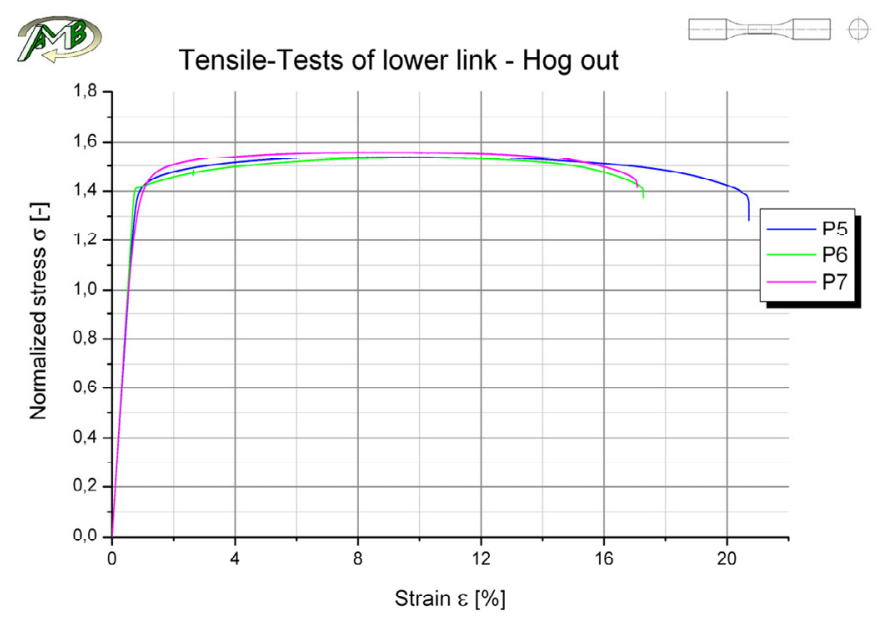

Fig. 10. Tensile test results for the flat specimen out of hogout lower link fittings.

lifetime. The slopes of the curves are very similar. For a statistical analysis the number of specimen is too low.

\subsection{Fracture crack growth rate tests}

Figure 14 shows the test results of the SENB-specimen taken out of forged lower link fittings. A vertical line passing through the least value of $\Delta K$ was obtained, in order 


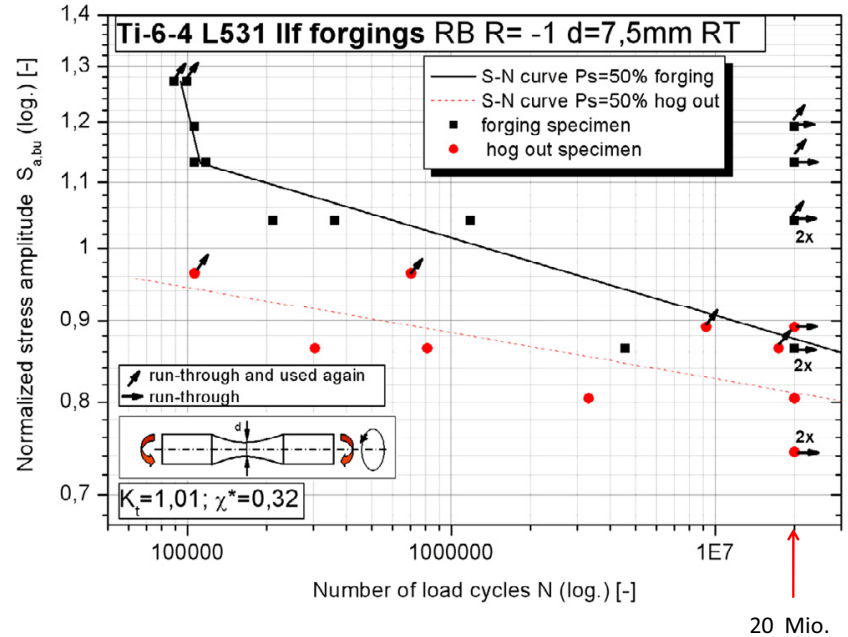

Fig. 11. Comparison of S-N curves for forging and hog-out.

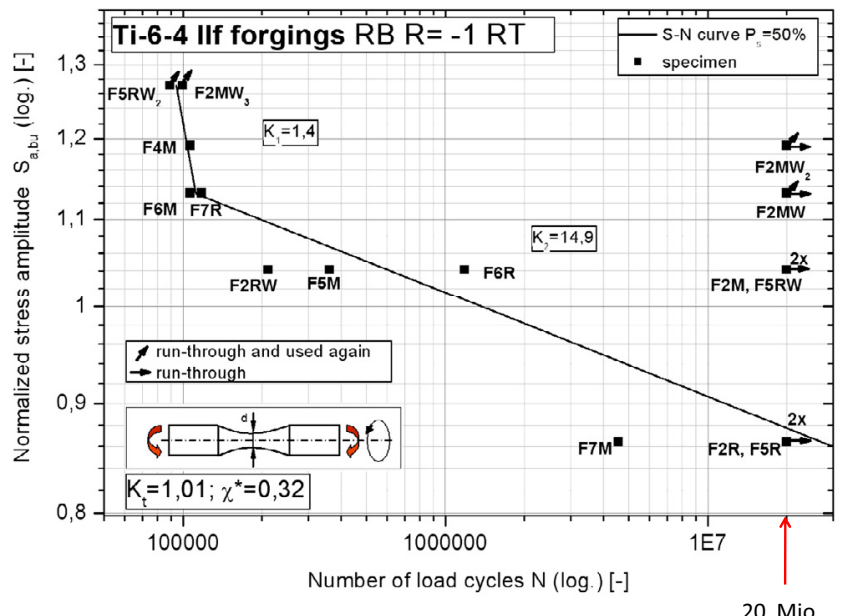

Fig. 12. S-N curve for forging lower link fittings.

to determine the threshold of the stress intensity. A fit out of the straight part of the date point was achieved to find out the slope $m$ of the Paris-line.

In Figure 15 the fracture mechanical test result of the hog-out specimen is shown.

The stress intensity threshold is similar for both investigated microstructures. The slope of the Paris-Erdoganequation is shallower for the forged specimens. Further on, the scatter band of the bi-modal SENB-specimens (forged part) is significantly smaller than the lamellar microstructure (hog-out).

\subsection{Components test - lower link fitting}

Both form of the titanium lower link fitting - hog-out and forging were investigated under two constant amplitude levels. The detailed test run and results are mentioned in following section.
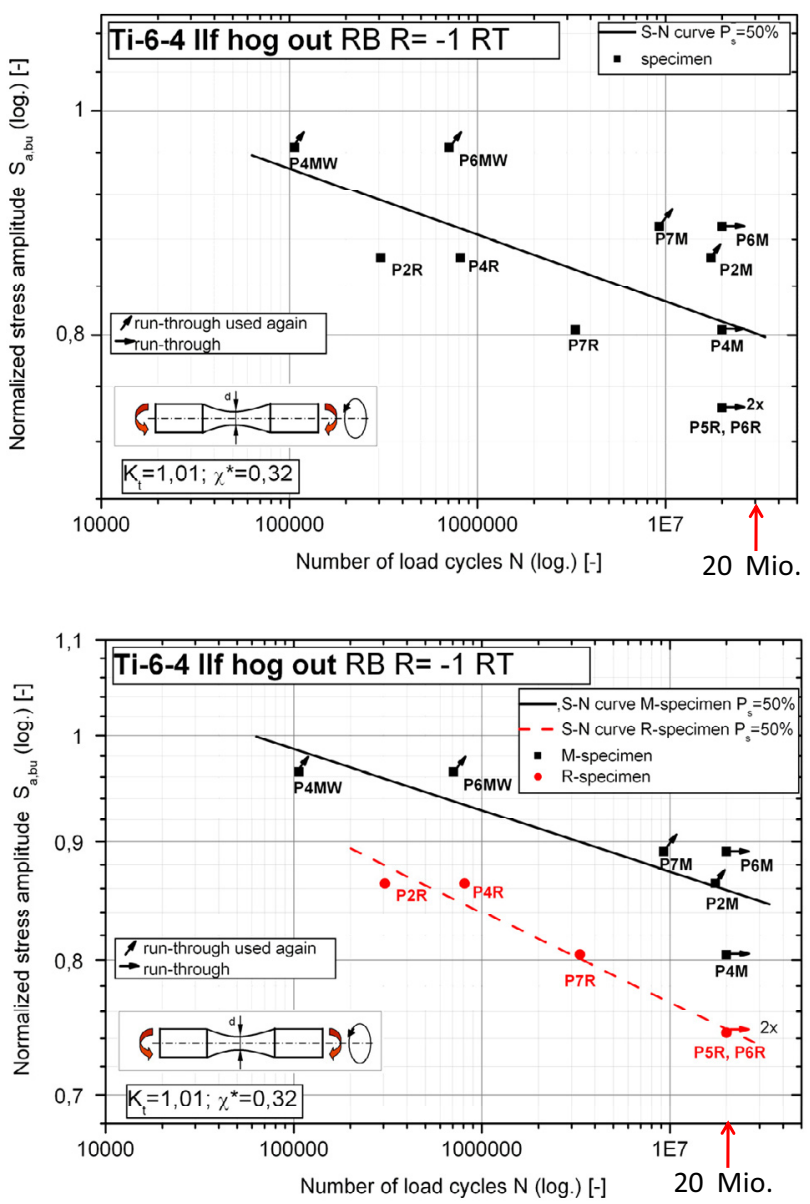

Fig. 13. S/N curve for hog-out lower link fittings together (up) and separated (down).

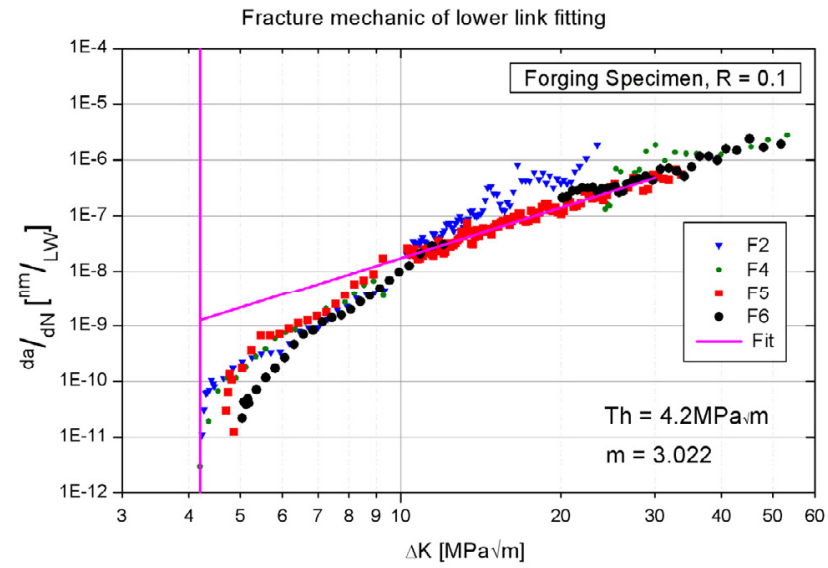

Fig. 14. Fracture mechanical test result of forging specimens.

\subsubsection{Constant amplitude fatigue tests}

As shown in the following table, the life-time of the forged parts at the high-cycle-fatigue tests is lower than that of the tested hog-outs. It can be seen that the forged parts are more sensitive against fretting fatigue than the hog-outs. 


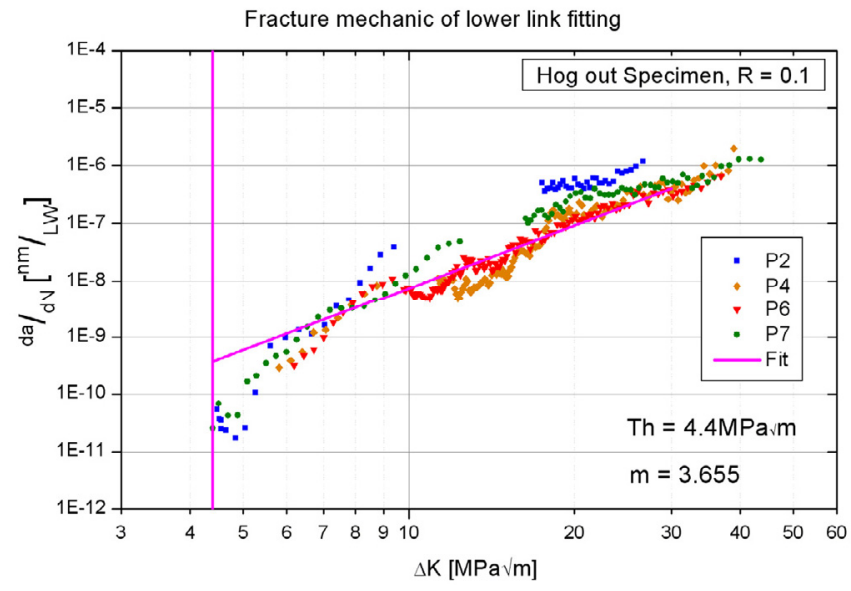

Fig. 15. Fracture mechanical test result of hog-out specimens.

Table 3. Life cycles Ti-6-4 hog-outs.

\begin{tabular}{ccc}
\hline Ti hog-out & Life time cycles & $F_{\max }[\mathrm{kN}]$ \\
\hline 2 & 20410 & 118 \\
3 & 12078 & 118 \\
4 & 8768 & 118 \\
5 & 58054 & 80 \\
6 & 72531 & 80 \\
7 & 53627 & 80 \\
\hline
\end{tabular}

To achieve an identical damage level for life cycles, a characteristic increase in the relative displacement was evaluated. The displacement was measured by the integrated LVDT-sensor of the hydraulic actuator.

\subsubsection{Hog-outs}

The lower load level was tested with an increased frequency of $5 \mathrm{~Hz}$, which had no influence on the temperature during the tests. Specimens two and four have been tested in normal load direction, whereas the other specimens were tested in inclined load direction.

An external force of $120 \mathrm{kN}$ was applied to the lower link fitting. All finite element plots used a deformation plot scale of 10:1. Due to a decrease of $28^{\circ}$ in the load angle, the demands on the connecting bolt and pins between fitting and fixture were significantly reduced. The load conditions on the lugs are well comparable.

Due to the change in the direction of loading, stiffness of the part increases, this in turn reduces the maximum displacement from $1.3 \mathrm{~mm}$ to $0.6 \mathrm{~mm}$ at nominal load.

The oscillating crack propagation for the titanium hog-outs can be seen clearly in the following figures. Keeping in view the load direction in specimen two and four, all crack surfaces which were investigated were found to be comparable to each other.

The crack initiation is mostly normal to the load direction, independent of the global angle of the load, see Figure 18. The crack initiation area is congruent with the highest uniaxial tensile loaded area of the lug, which leads to a local relative maximum in displacement and velocity
Table 4. Life cycles Ti-6-4 forgings.

\begin{tabular}{ccc}
\hline Ti forging & Life time cycles & $F_{\max }[\mathrm{kN}]$ \\
\hline 2 & 11152 & 118 \\
3 & 10008 & 118 \\
4 & 12332 & 118 \\
5 & 42779 & 80 \\
6 & 26670 & 80 \\
7 & 38912 & 80 \\
\hline
\end{tabular}

between the lower-link-fitting lug and the bushing. These local ambient conditions highly encourage fretting.

The inclination of the single or two sided crack lines is mostly identical. At the lower load level a single sided crack initiation can occur, whereas at the higher load, a double sided crack initiation could be found. The constant amplitude fatigue tests for titanium parts lead to the life cycles shown in Figure 19. The experimental S-N curve shows good compliance to the nominal specified life at high stress levels. A decrease in lifetime can be observed at lower loads. As an assumption, fretting ought to be the main damage mechanism.

By observing the crack growth area, by using a stereographic light microscopy, both crack initiation and, crack growth channel can be clearly detected. The crack initiation is based on contact fretting, which can be found at the lug. The size of the oscillating crack growth channel depends on the load level; while the formation is independent of the height of the applied load.

\subsubsection{Forgings}

All tests were performed with an inclined loading. The oscillating crack run can be seen in the following figures, whereas double sided cracking occurred at both load levels.

At the load level of 0.67 the portion of the rapid burst area is increased, which is evident from the major deflection on the crack surface.

The inclination of the crack surface is identical in all forgings. As described above, the crack starts in the tension loaded area which is orthogonal to the external force direction of the lug. The life cycles of the lug are depicted as an S-N curve in Figure 19.

The median lifetime of the titanium forgings is reduced to a value of 36000 cycles from about 61000 cycles of the hog-outs by the same absolute scatter. The evaluation was repeated using displacement measurement of a piston, actual stiffness of the (cracked) fitting of which was presented as the crack opening displacement. This states an earlier start of the fretting initiated crack growth as well as a quite high crack growth rate. Because of the higher static strength values of the forging, the burst cracking happens at a quite small remaining area.

\subsubsection{Variable amplitude tests}

The variable amplitude tests for both titanium in the form of both hog-out and forging were carried out. The 

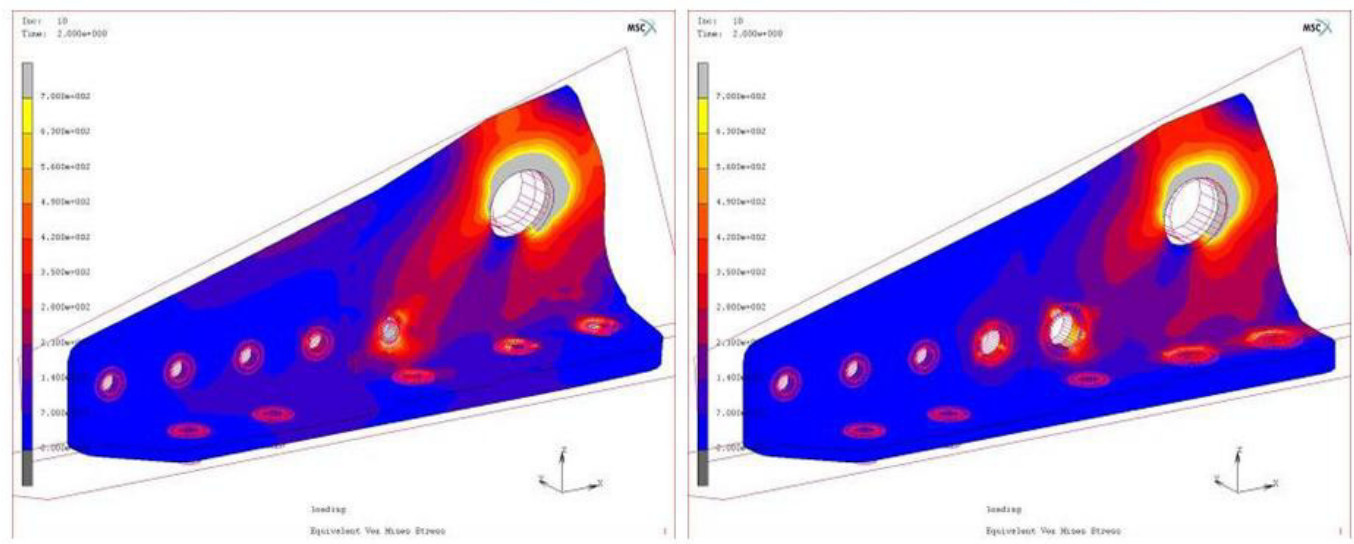

Fig. 16. Equivalent von-Mises stress at normal/inclined load direction, Ti-6-4.
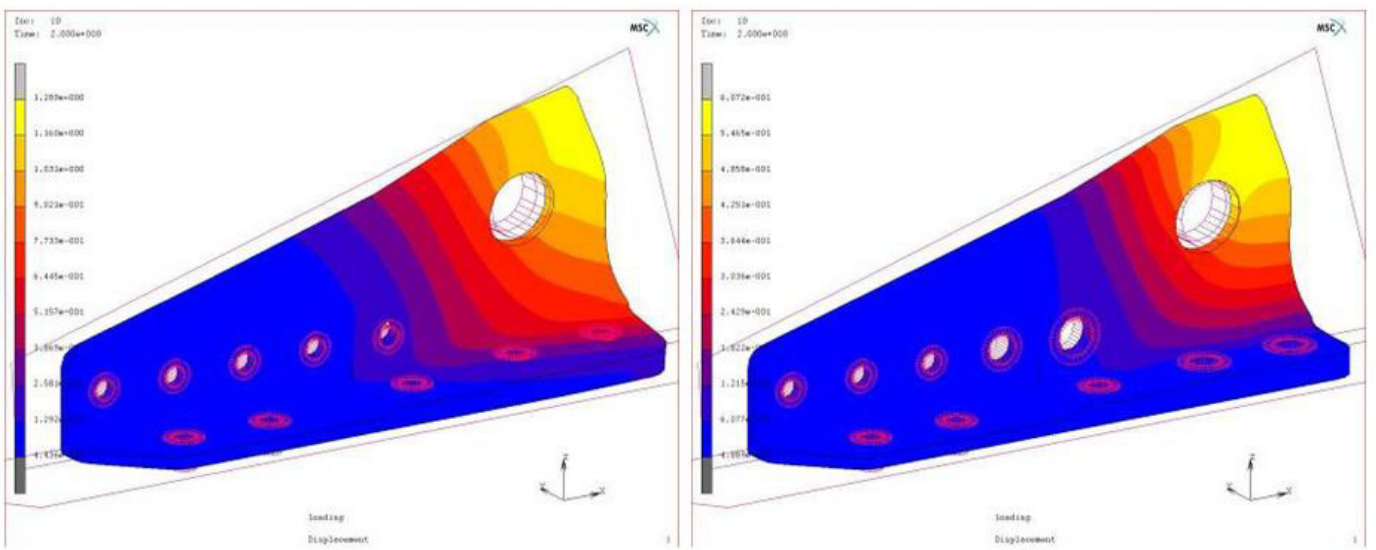

Fig. 17. Displacement at normal/inclined load direction, Ti-6-4.
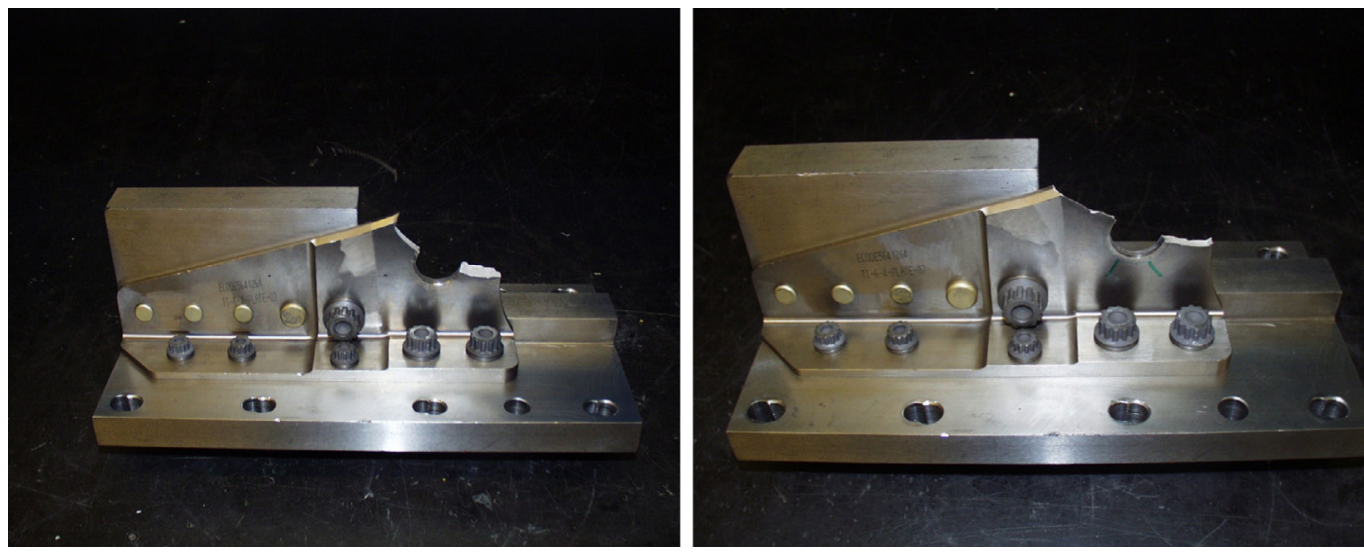

Fig. 18. Global crack run in tested titanium lower link fittings, hog-out \#02 (left) and hog-out\#06(right).

hog-out passed the collective while the forging failed before passing the collective in total. A graphical overview over both load collectives and the results are given in Figure 21.

Figure 22 shows the crack run of both lower link fitting after variable amplitude test. The forging cracked through earlier, but the crack initiation can be estimated at same cycle level as hog-out. This verifies the assumption of the higher notch-sensitivity of the forged titanium fitting.

\section{Fracture analysis}

For the metallographic analysis, the fracture surfaces as well as the microstructures of different metallographic 


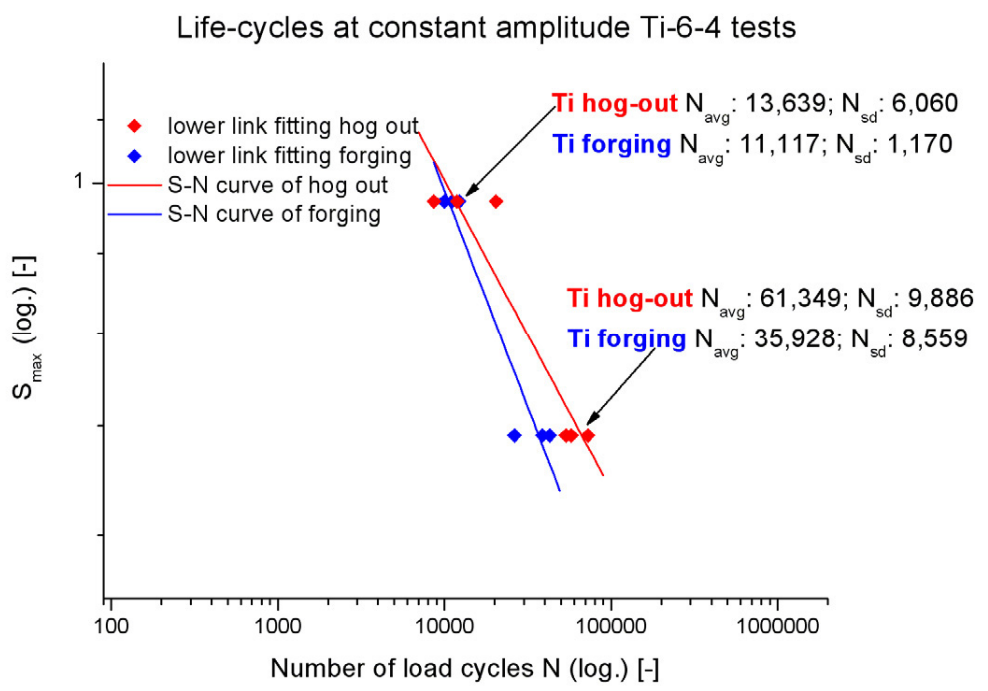

Fig. 19. Life-cycles of titanium fittings (hog-outs and forgings) at constant load.
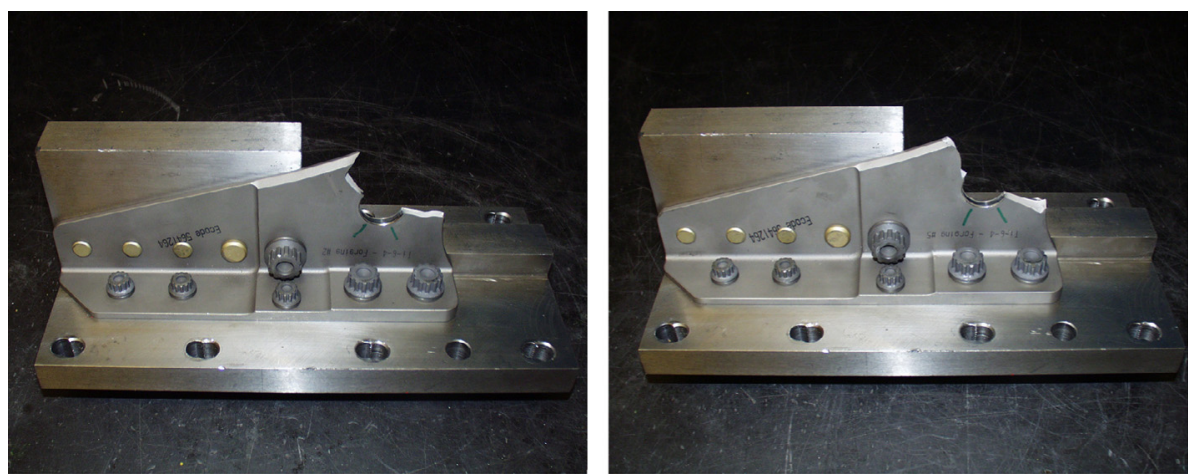

Fig. 20. Global crack run in tested titanium lower link fittings, forging \#02 (left) and forging \#05 (right)

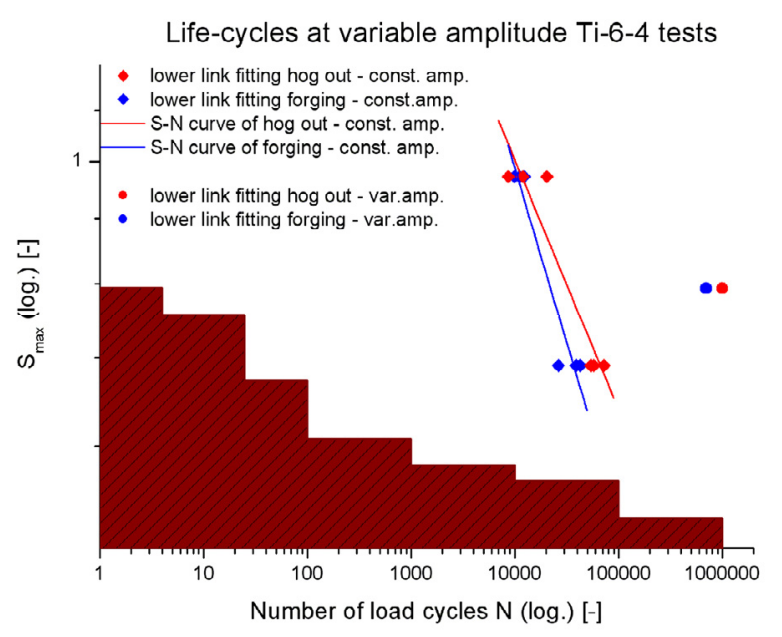

Fig. 21. Life-cycles of titanium fittings (hog-outs and forgings) at variable load.

sections of specimens and components were investigated. Therefore, a light microscope (LOM), a laser confocal microscope (LEXT) and a scanning electron microscope (SEM) were used.

\subsection{Analysis of specimen of rotating bending tests}

An overview of the investigations of the specimens carried out, is shown in Figure 23.

\subsubsection{Fracture surfaces}

The fracture surfaces were investigated for both forged and hog-out lower link fittings to understand the large variation in the cyclic lifetime at same stress levels.

A typical fracture surface of a forged lower link fitting is shown in Figure 24 (left) where a fine and homogenous fracture surface is observed. However, the one on the right is showing a rough fracture surface with manufacturing tracks. The latter in the fracture surface of a hog-out lower link fitting.

Figures 25 and 26 show two fracture surfaces tested at the stress level of 1.04 and 1.27 with a large difference in the forged specimen lifetime values. The SEM images show that the crack growth behaviour, considering the 

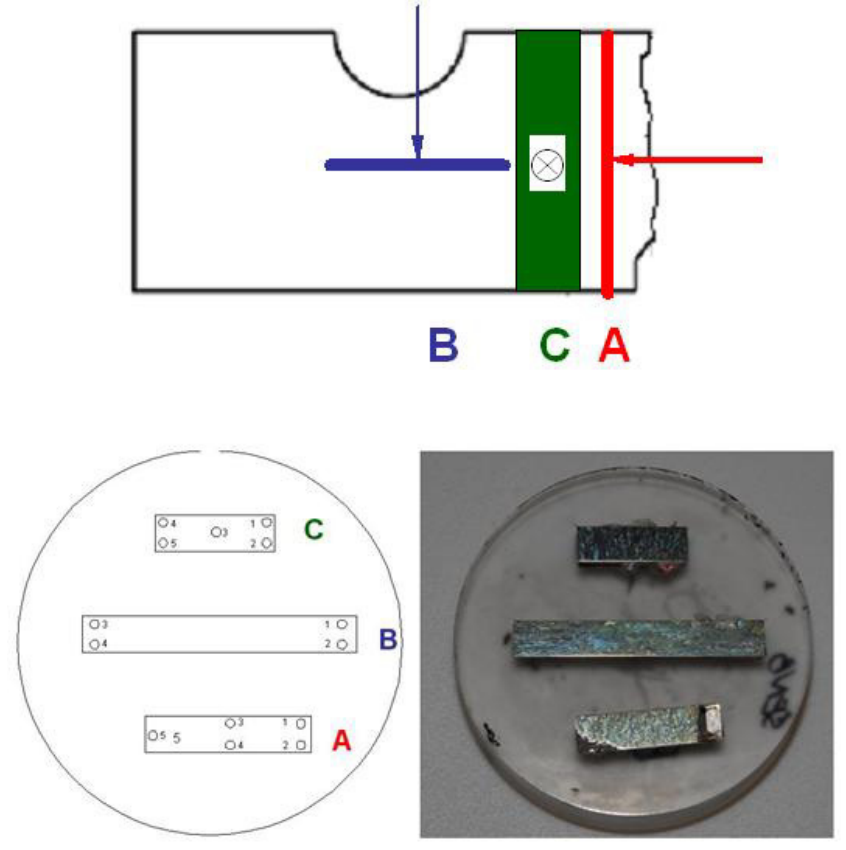

Fig. 22. Global crack run in variable tested titanium lower link fittings, hog-out (left) and forging (right).

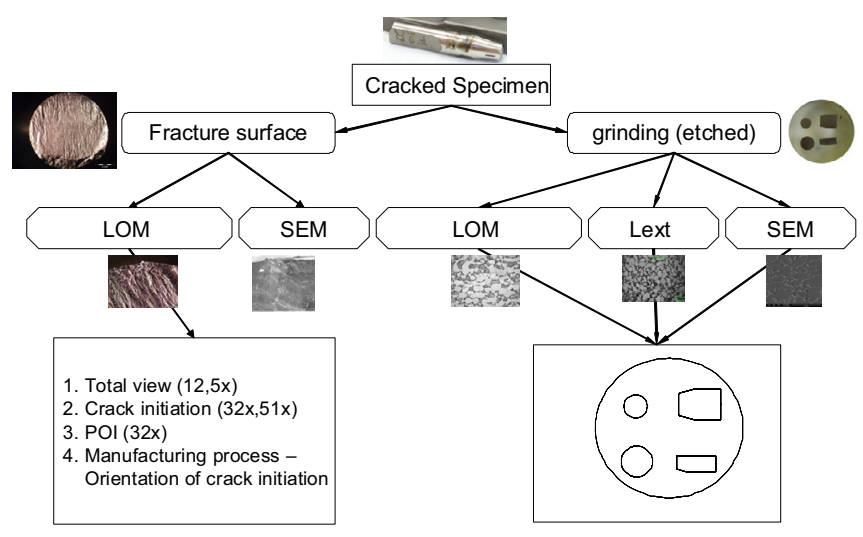

Fig. 23. Metallographic analysis.

adequate striation distance, is different for the specimen made of F2 and F5. Both specimens are made from the outer edge of the specific forged lower link fitting.

Figures 27 and 28 compare two fracture surfaces of hog-out specimen, tested at stress level of 0.86 which possess a wide difference in their lifetime.

LOM and SEM metallography shows that the hogout specimen with a low number of cycles has a coarse structured surface with lamellar microstructure. With increasing number of cycles the surfaces become finer. This relation is confirmed by other hog-out specimen as well.

\subsubsection{Microstructural investigation}

Further information about the lifetime behaviour can be obtained by investigating the microstructure at several orthogonal cutting planes. Therefore metallographic sections have been obtained and etched. Figure 29 shows a cutting plan and the investigated points of interest.

Figure 30 shows no major microstructural difference for the forged lower link fittings at the stress level of 1.04 . Both microstructures are bimodal with similar alphacontent.

Figure 31 shows that a decrease in the size of secondary alpha colonies improves the lifetime considerably. Further on, there are strong texture tracks recognizable at higher lifetimes. Improved microstructure leads to higher number of cycles in the fatigue analysis.

The microstructures of the forging and hog-out lower link fittings are shown in Figure 32. The bimodal microstructure of the forged material leads to an improved lifetime as compared to the lamellar microstructure of the hog-out.

\subsection{Analysis of specimen of fatigue crack growth tests}

For metallographic analysis, the fracture surfaces from different orthogonal metallographic sections were investigated as shown in Figure 33.

Figures 34 and 35 show the microstructure for forging and hog-out SENB-specimen at three different positions. Investigations were carried out at different locations on each of the specimen. Due to the homogeneity observed in the microstructures, the microstructure at the location 1 is presented below. The images were taken using a magnification of $500 \times$ using a light microscope. All investigated points of the forging show a bimodal microstructure and a slight texture is found in section B.

For the hog-out SENB-specimen, different microstructures were observed at different positions. The microstructures of the hog-out are coarse lamellar structure.

\subsection{Analysis of components}

\subsubsection{Fracture surface}

In order to allow a crack surface of the lower-linkfittings which is not completely cracked throughout, the upper part has been cut-off. The analysis of the crack surface using LM can be seen in Figure 36. Comparing the shape of the crack growth channel from hog-outs and forgings, a wide agreement is found. However, the forged specimens give a rather fretting trace, which also declares the shorter lifetime of the forging specimens.

\subsubsection{Microstructure}

The microstructure was evaluated at different regions throughout the lower link fitting after the component test. Figure 37 shows the different positions at which the microstructure analysis was carried out.

Figure 38 shows the results of the first investigations for forging and hog-out. While, Figure 39 shows the metallographic sections which are based on additional results of a rotating bending specimen. 

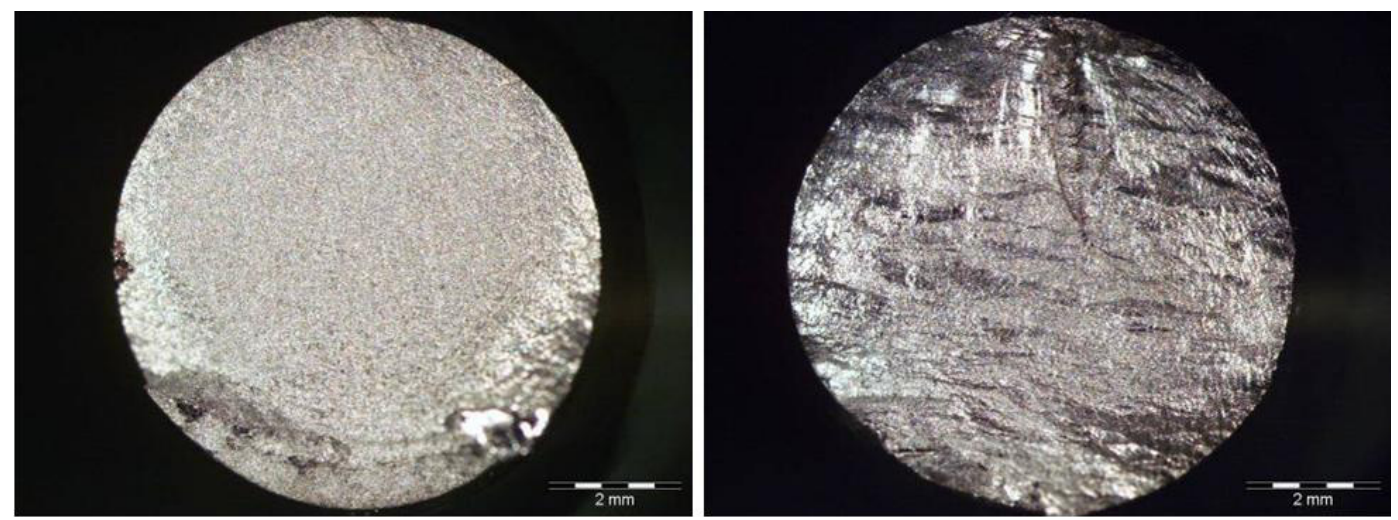

Fig. 24. Typically fracture surface of forging (left) and hog-out (right).

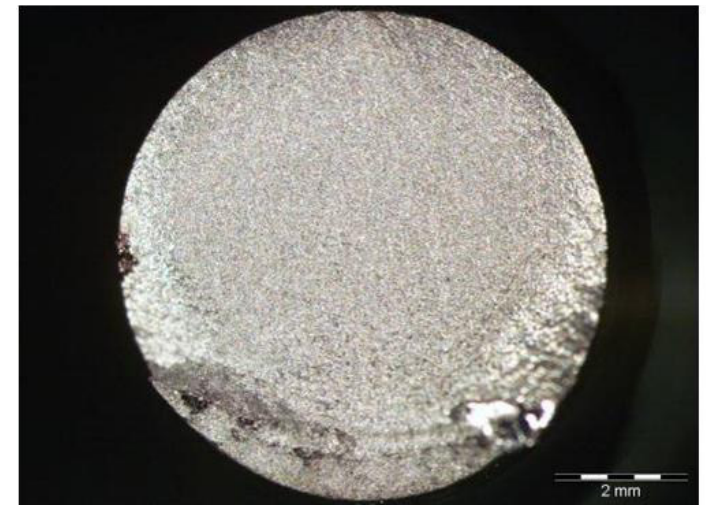

F2R, Stress level 1.04; 213,500 Cycle

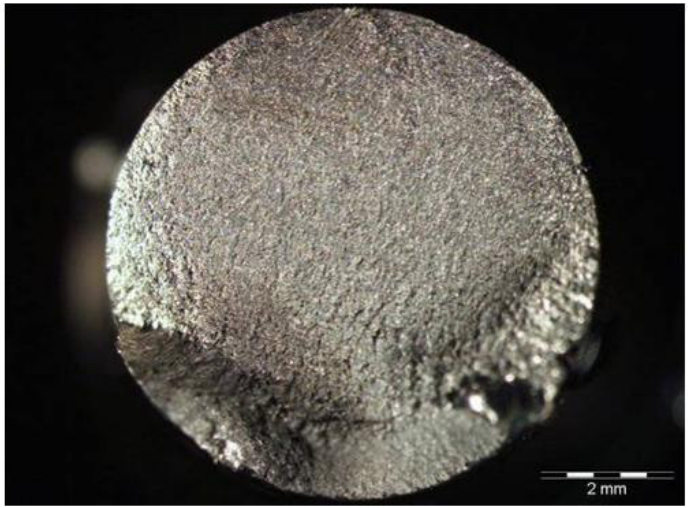

F5R, Stress level 1.04; 2.E7 Cycle

Stress level 1.27; 89,100 Cycle

Fig. 25. LOM of fracture surfaces of forging at a stress level of 1.04.

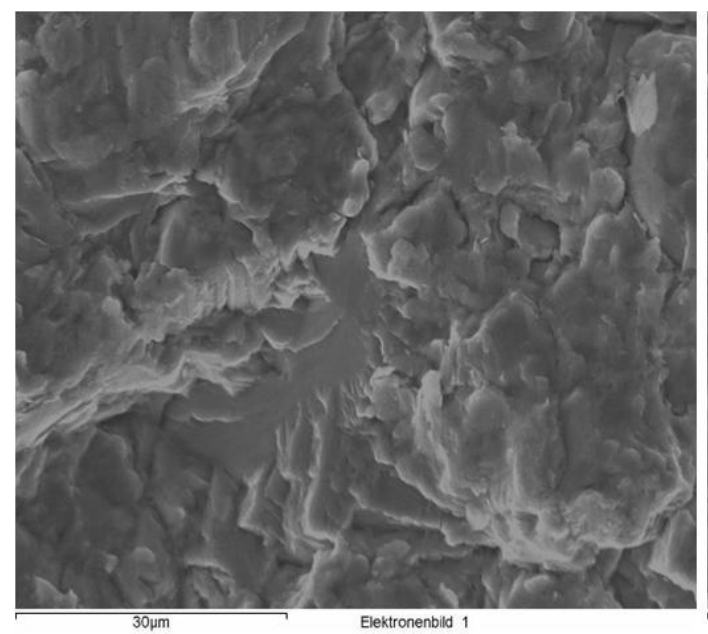

F2R, Stress level 1.04; 213,500 Cycle

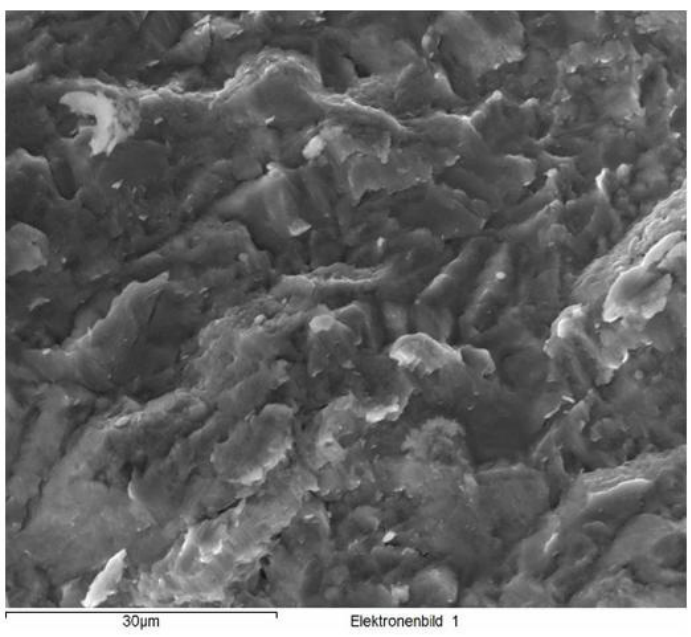

F5R, Stress level 1.04; 2.E7 Cycle

Stress level 1.27; 89,100 Cycle

Fig. 26. SEM of fracture surfaces of forging at a stress level of 1.04. 


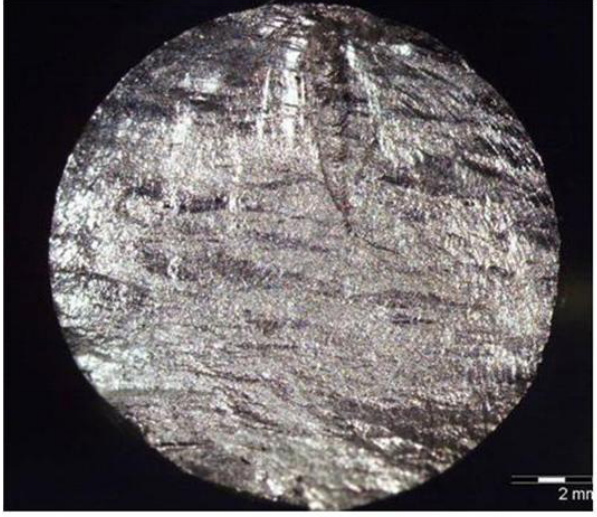

P2R, Stress level 0.86; 305,400 Cycle

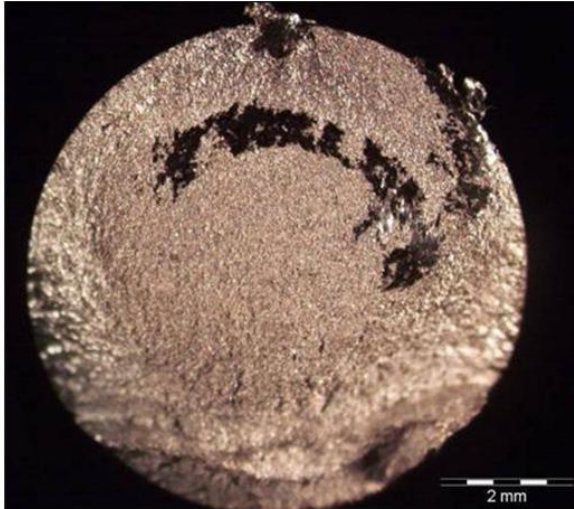

P2M, Stress level 0.86; 17.4E6 Cycle

Fig. 27. LOM of fracture surfaces of hog-out at a stress level of 0.86.

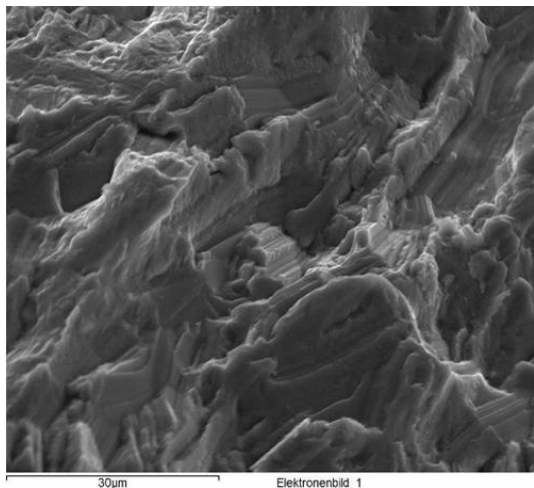

P2R, Stress level 0.86; 305,400 Cycle

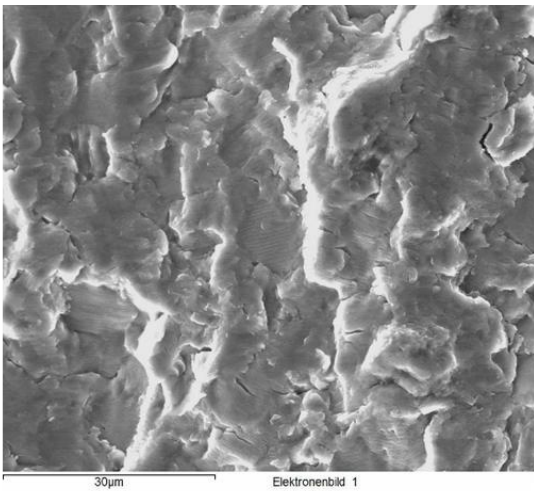

P2M, Stress level 0.86; 17.4E6 Cycle

Fig. 28. SEM of fracture surfaces of hog-out at a stress level of 0.86 .

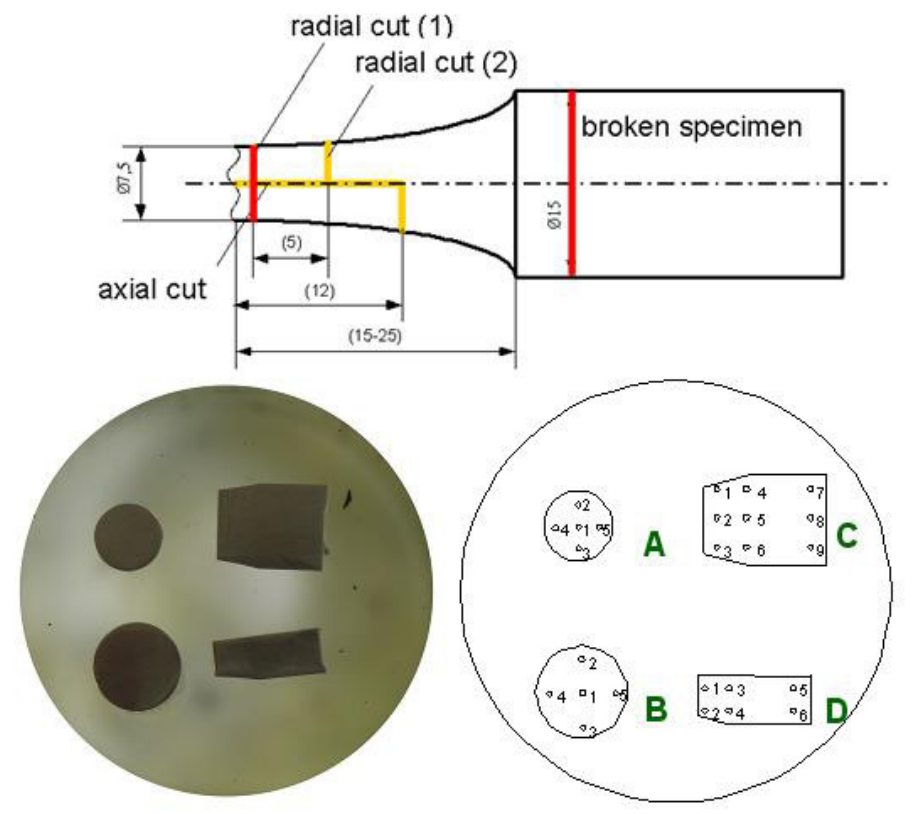

Fig. 29. Cutting plan and points of investigation. 


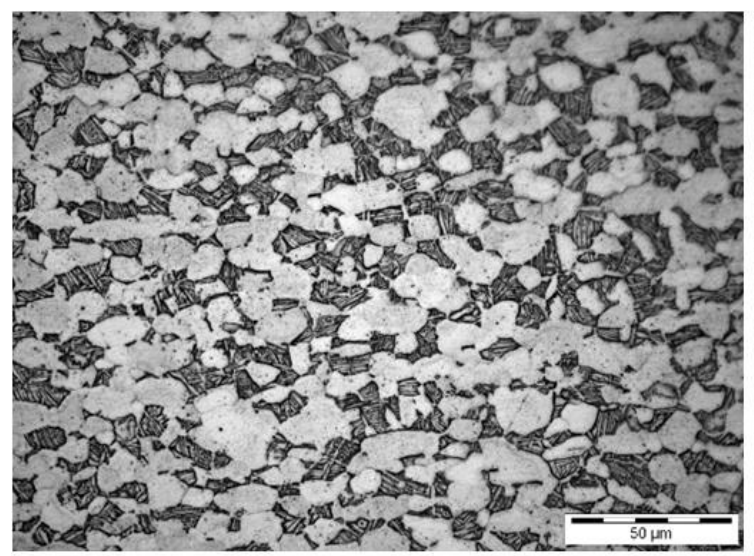

F2R, stress level 1.04; 213,500 Cycle

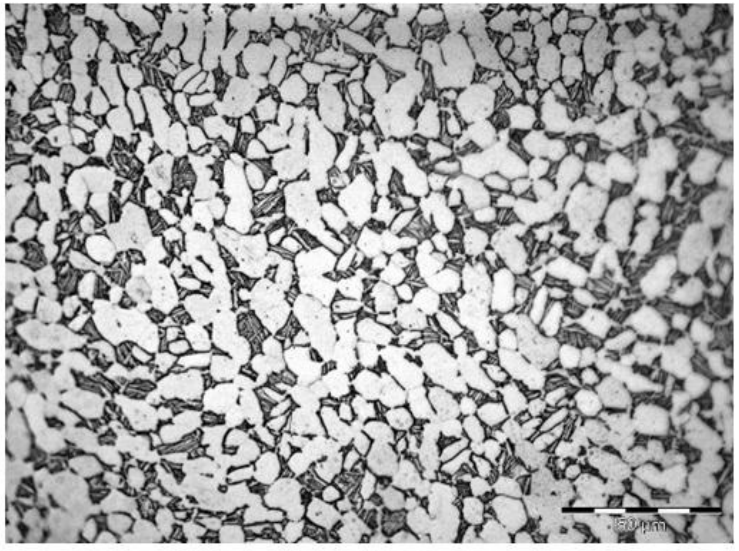

F5R, stress level 1.04; 2.E7 Cycle

(stress level 1.27; 89,100 Cycle)

Fig. 30. LOM of metallographic sections of forging at a stress level of 1.04 .

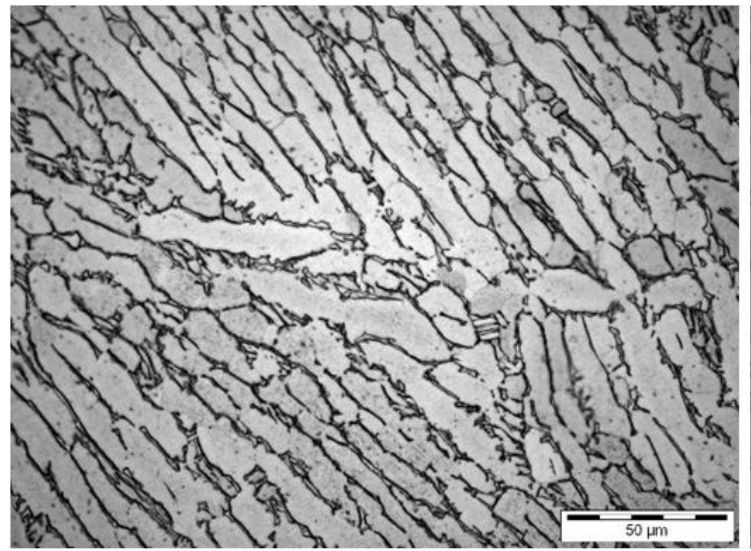

P2R, stress level 0.86; 305,400 Cycle

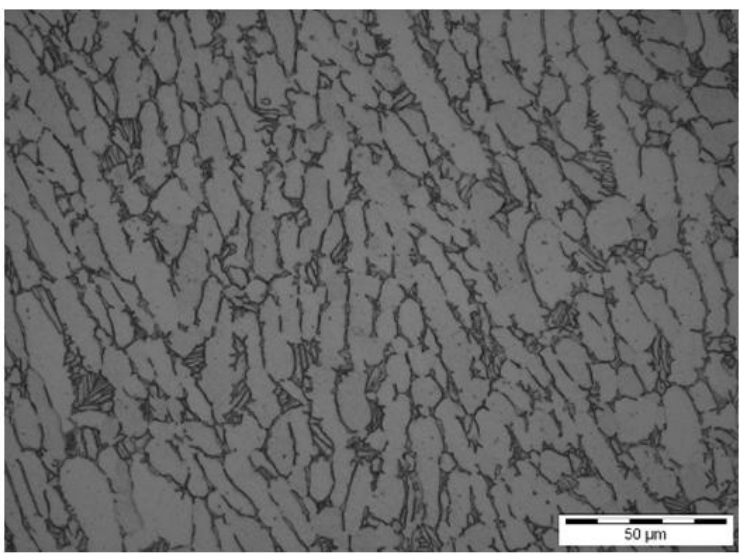

P2M, stress level 0.86, 17.4E6 Cycle

Fig. 31. LOM of metallographic sections of hog-out at a stress level of 0.86 .
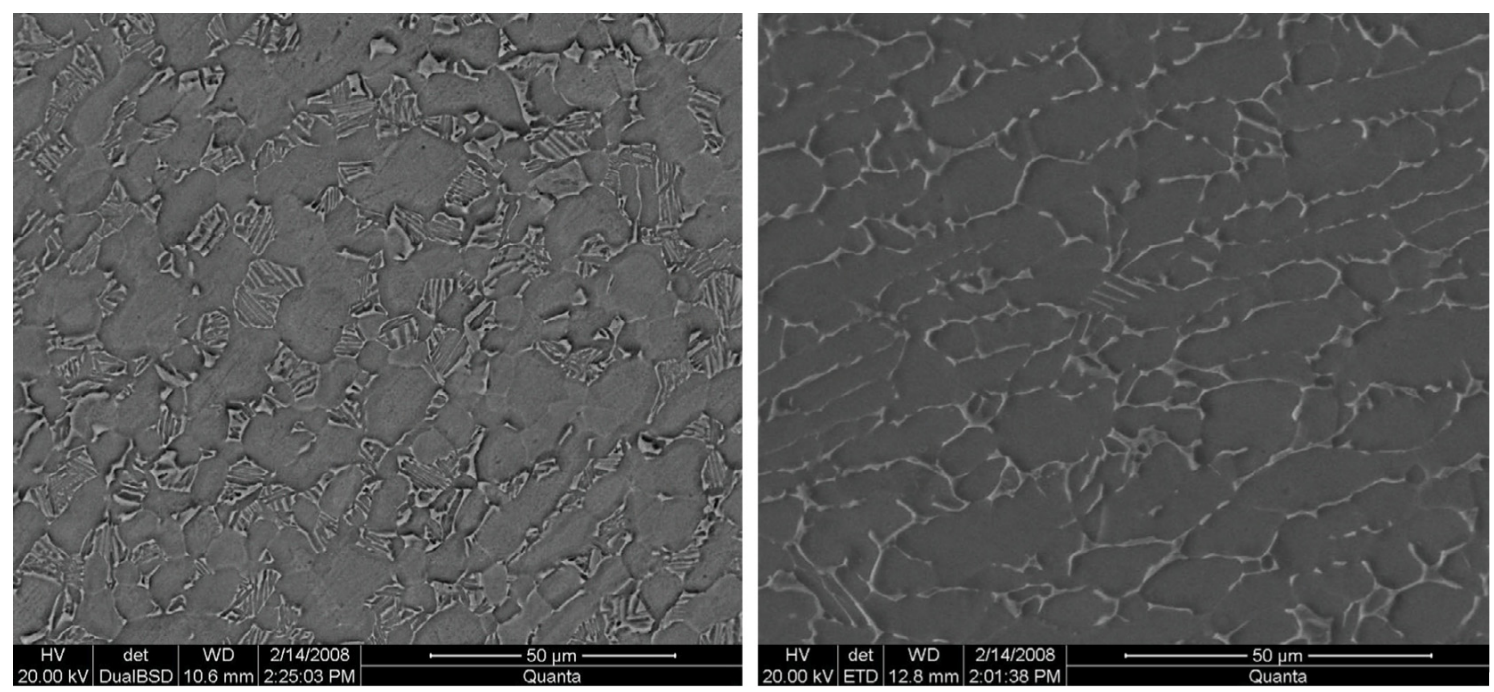

Fig. 32. SEM details of the microstructure of forging (left) and hog-out (right). 

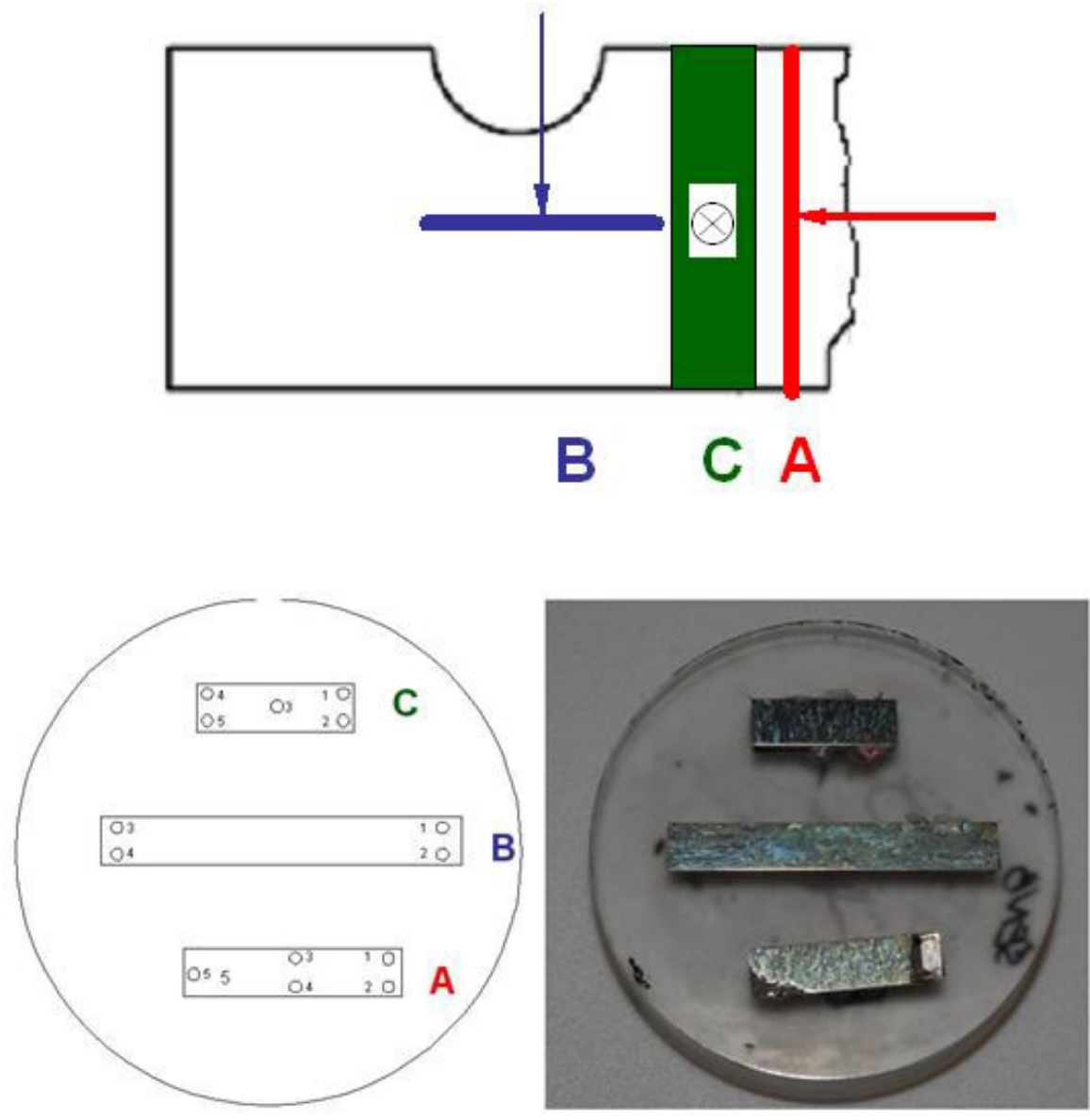

Fig. 33. Cutting plan of fracture surface and grindings.
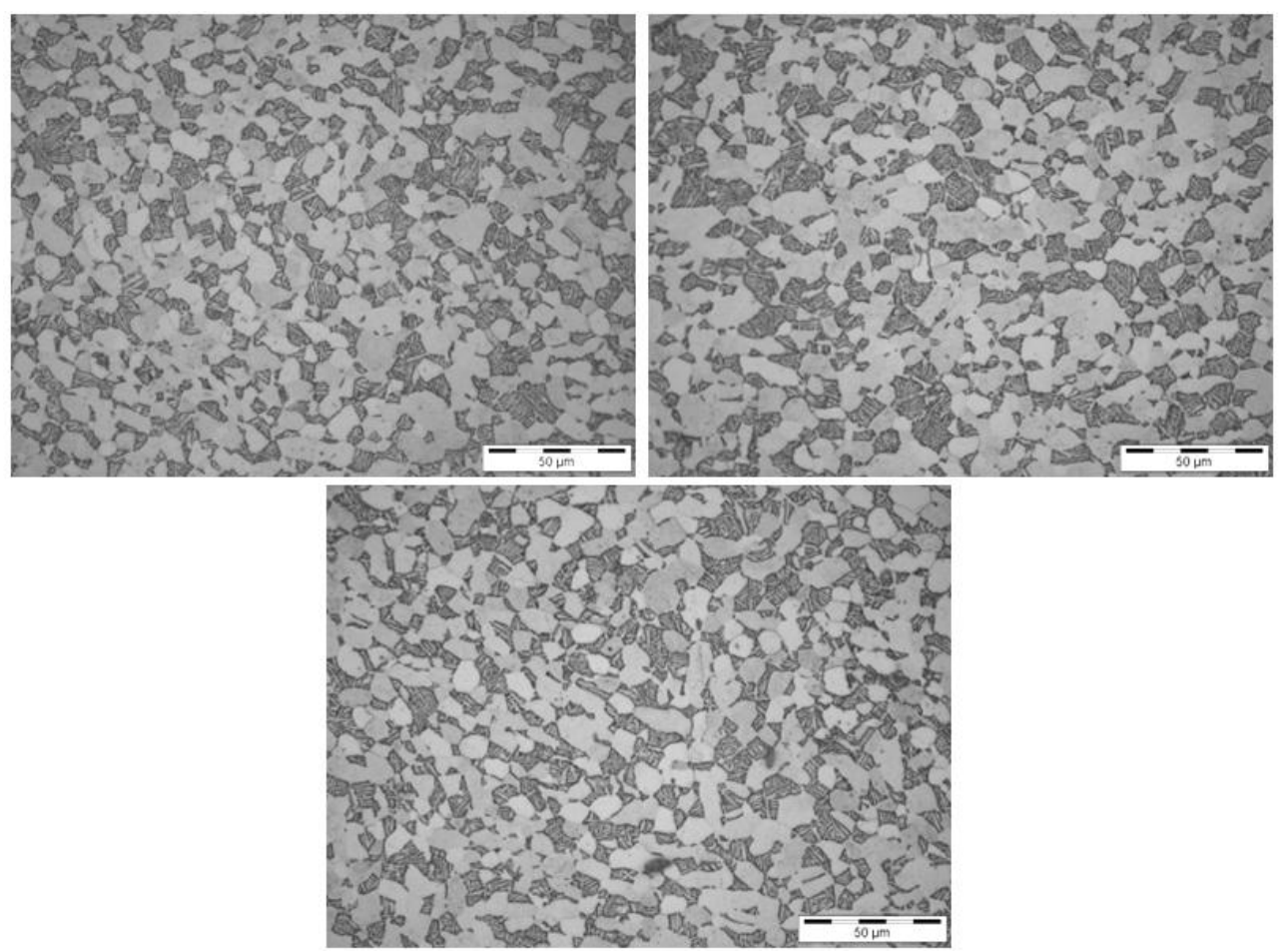

Fig. 34. Microstructure for forging at three different positions $(\mathrm{A}=$ top left, $\mathrm{B}=$ top right, $\mathrm{C}=$ down). 

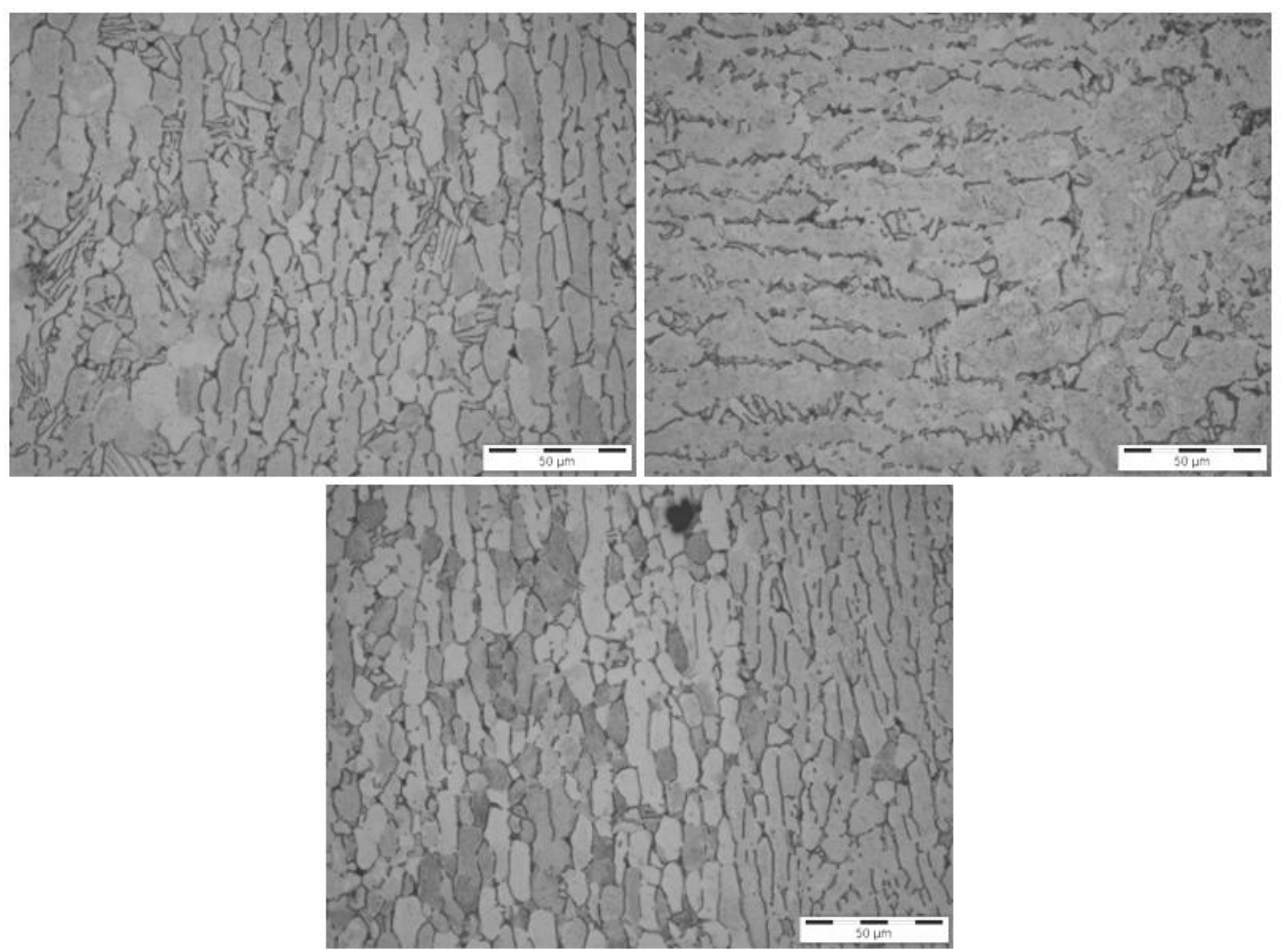

Fig. 35. Microstructures of hog-out at three different positions $(\mathrm{A}=$ top left, $\mathrm{B}=$ top right, $\mathrm{C}=$ down$)$.
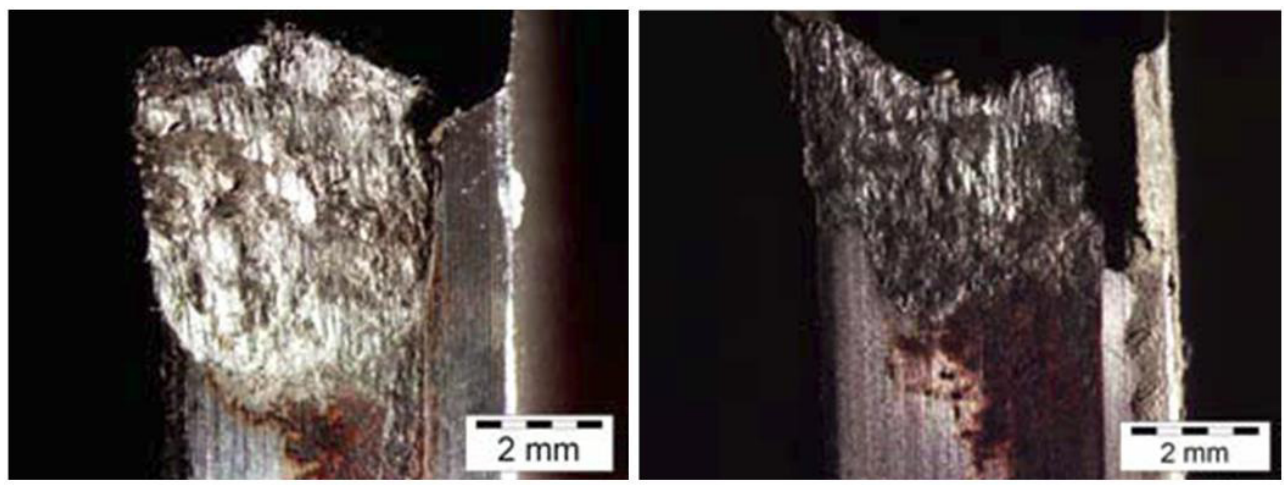

Fig. 36. Fracture surface of hog-out (left) and forging (right) specimen.

Owing to the major local dependency of the microstructure, additional points near the lug were chosen for additional metallographic investigation (see Fig. 40).

Figure 41 shows the homogenous bimodal microstructure of different positions of the forged-lower-link fitting illustrated in Figure 40.

In Figure 42, different microstructures of lamellar and textured hog-out lower link fitting metallographic sections arranged near the lug are shown. Beside the dominant lamellar structure, local regions (pos. 1-3) of bimodal textures of different shape were observed.

Summarizing these local microstructural images, including the fracture mechanical crack growth behaviour, and the results from the lower link fitting part tests, it has been stated that the hog-out shows a higher resistance to fracture growth due to the higher amount of beta-alpha-secondary-transitions. Such an example of a smaller size of primary-alpha-grains is seen by comparing the microstructural images taken from point 1(1) and 3(1) for forging and hog-out.

\section{Lifetime calculation with FEMFAT}

The lifetime calculation is implemented with the software program FEMFAT. The stress analysis of the lower link fitting, see Figure 16, and the global load data agreed with the force applied in the experimental tests, are required for the input. In this case, the global load was carried out with the finite element solver MSC Nastran. The material data was determined by the specimen tests mentioned above. The load history is represented in one cycle and so the calculated damage represents the inverse number of cycles to failure. The following are such 

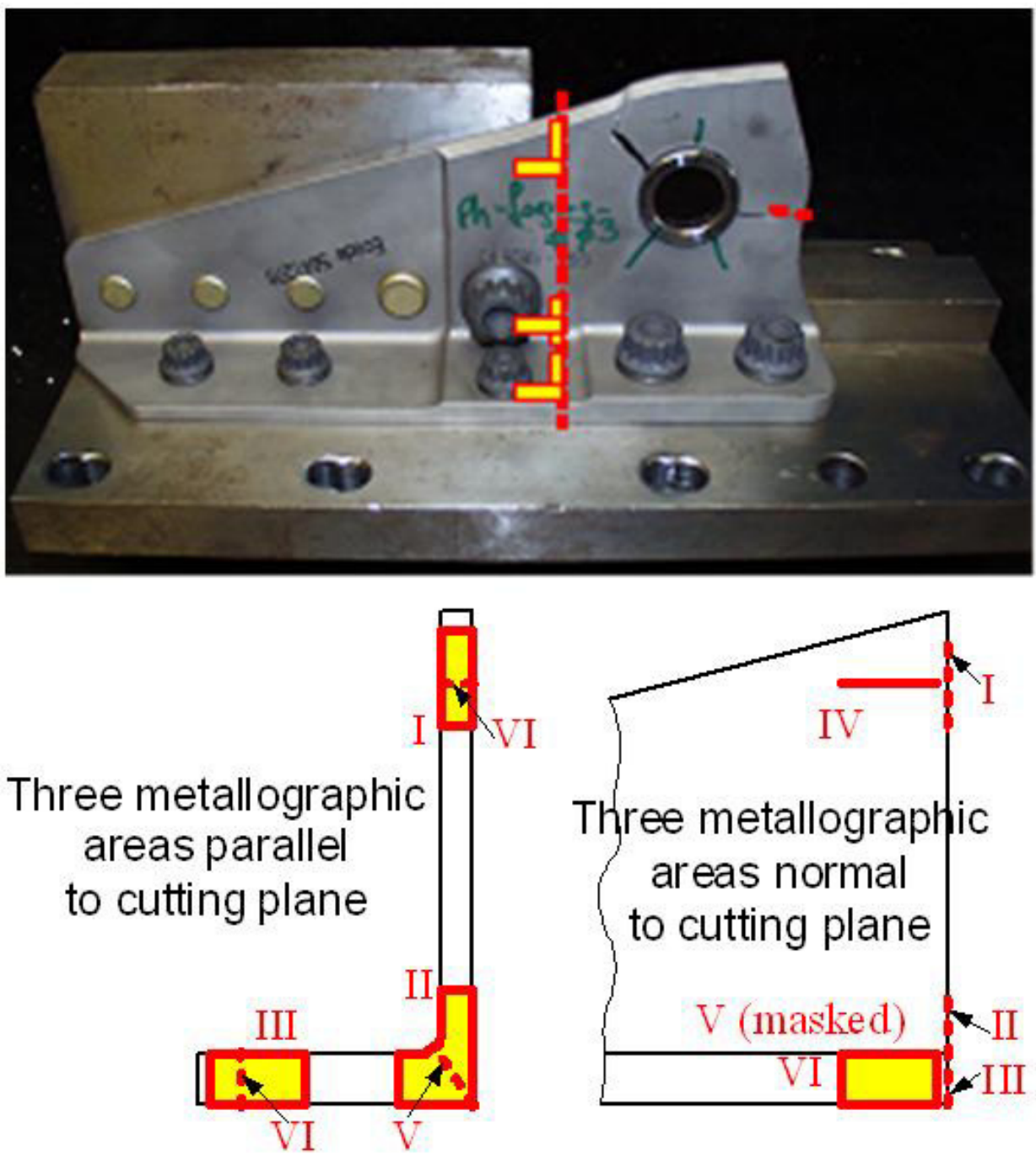

Fig. 37. Points of investigation of the microstructure in the former project.

influences which were also considered for the lifetime calculation: stress gradient, load art, mean stress and mean stress shifting, influence of the surface layer such as roughness and shot peening [3-5]. The main criterion is fatigue assessment based on the local nodal stresses using the local stress gradient to reflect the supporting condition of the material. The Miner-law is used as damage criteria, the local multiaxial condition is considered by the critical-plane approach. Main influence parameters are therefore the material dependent stress gradient and $\mathrm{S} / \mathrm{N}$-curves from specimen tests. The input parameters are taken from the FemFat-database and completed by static and dynamic tests for both investigated microstructures [6]. Figure 43 shows the result for the lifetime calculation with a load of $118 \mathrm{kN}$, which represents a maximum principal stress of $1150 \mathrm{MPa}$. The calculated lifetimes are 60569 cycles for hog-out and 45330 cycles for the forging. These proofs that the experimental results were quiet sufficient. The lifetime calculation for the lower load level of $80 \mathrm{kN}$, demonstrates a significant difference in the calculation results, in fact this gives a longer lifetime by a factor of ten. This result could be caused by the fretting effect which has a strong influence on the lifetime at high cycle fatigue level. Therefore, in future, the effect of fretting and other influence such as microstructure will be further investigated.

\section{Summary and outlook}

The tests results are satisfy and highlight improved fatigue behaviour for the forged specimen; while the fracture behaviour is for the hog-out specimen very similar with enhanced properties. The component tests at higher loading levels depict similar results, while at lower loading levels the hog-out specimen shows slightly better results. Regarding the crack initiation of the lower link fittings in the component tests, the influence of fretting affects the lifetime behaviour substantial. The interaction of different components compounded of different materials, like bolt, bushing or lug, involves extensive investigations on the lifetime regarding fatigue and fretting, as well as a 


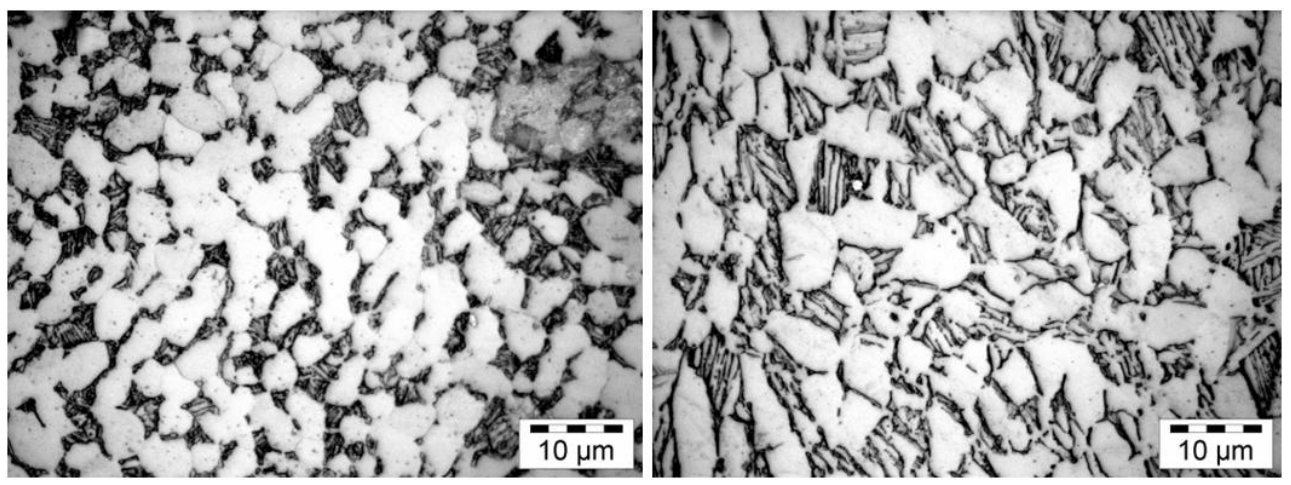

Fig. 38. Microstructure results of former investigations for forging (left) and hog-out (right).
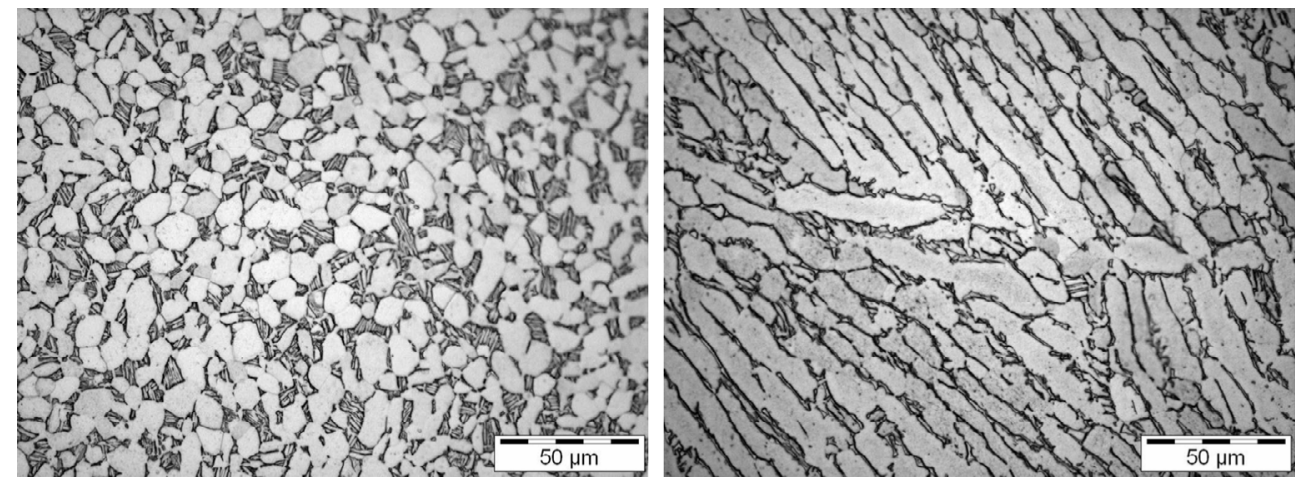

Fig. 39. Rotating bending specimen microstructure results for forging (left) and hog-out (right).

\begin{tabular}{|l|l|}
\hline $1(1)$ & - \\
\hline $1(2)$ & --- \\
\hline $2(1)$ & - \\
\hline $2(2)$ & --- \\
\hline $3(1)$ & - \\
\hline $3(2)$ & --- \\
\hline $4(1)$ & \\
\hline $4(2)$ & - \\
\hline $5(1)$ & - \\
\hline $5(2)$ & --- \\
\hline $6(1)$ & - \\
\hline $6(2)$ & --- \\
\hline $7(1)$ & - \\
\hline $7(2)$ & --- \\
\hline
\end{tabular}

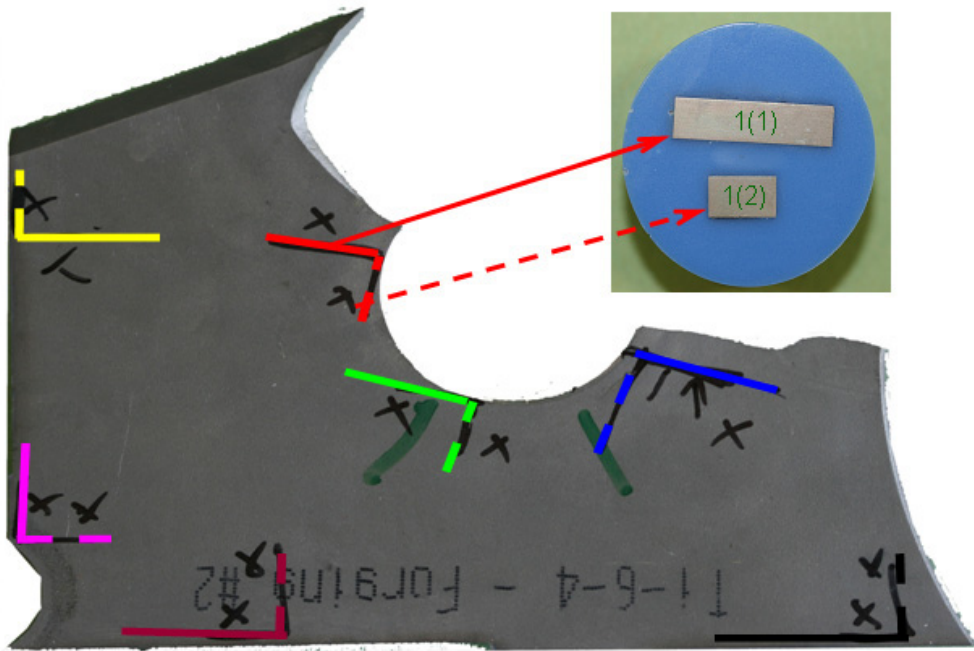

Fig. 40. Cutting plane for current microstructure investigations.

combined investigation, known as fretting fatigue. The investigations on the microstructure show a connection between the lifetime results due to the microstructure both in specimen tests and component test. If a technical crack is initiated due to fretting, the number of load cycles is decreased down for the investigated parts. The resistance to crack initiation and crack growth seems to be significantly influenced by the microstructure. The specimen from forging process holds better due to the controlled bi-modal, homogeneous microstructure, which provides higher fatigue resistance. For the component though, the bi-modal microstructure seems to be sensitive to fretting behaviour. At high loads, increased local deformation and high contact stresses occur and therefore fretting damage assesses a comparable high local energy density [7].

Regarding the former works, this investigation is the basis of lifetime approaches, which depends on the microstructure of the components and the aim of the future work. 

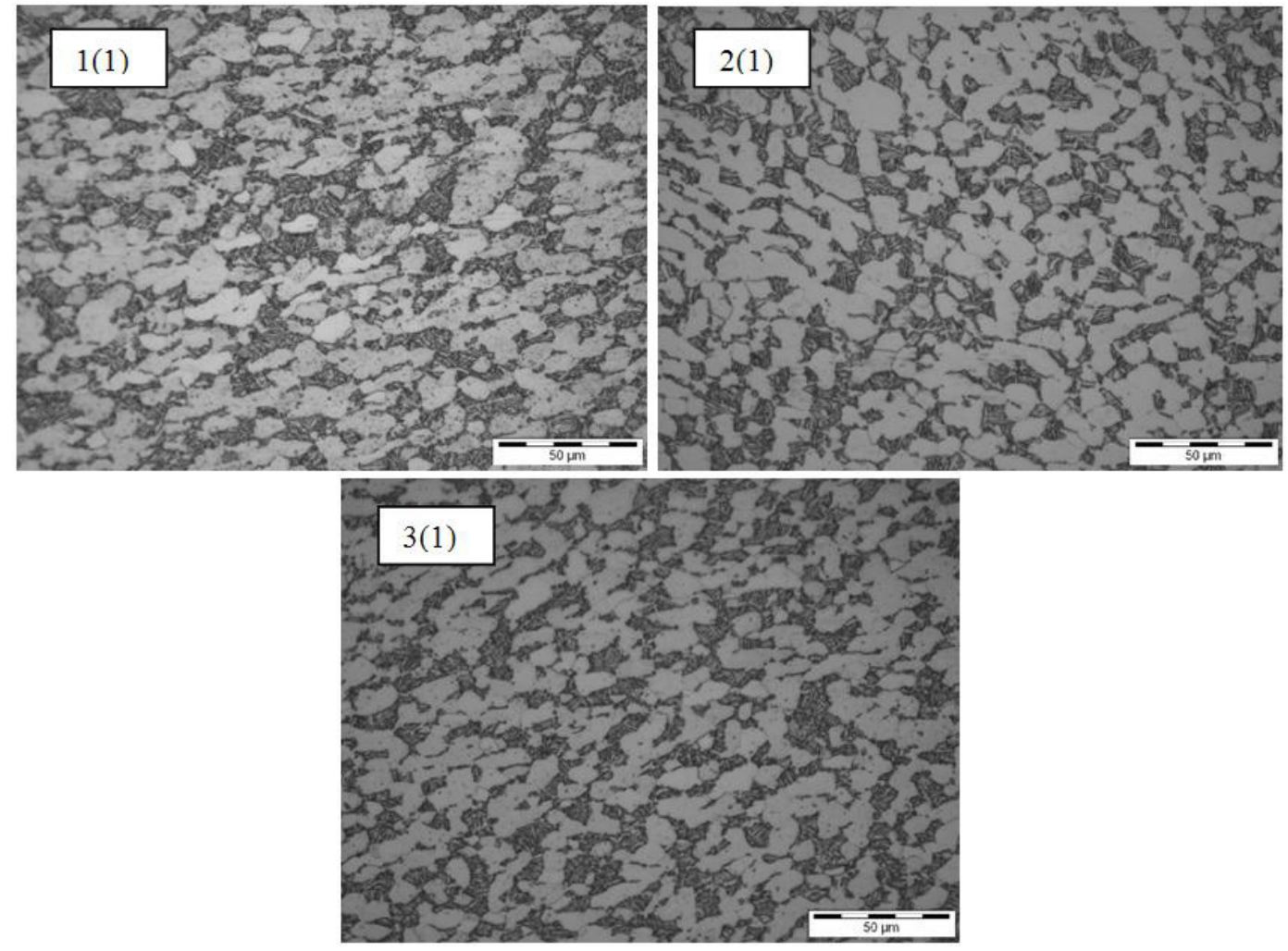

Fig. 41. Microstructure at different positions for forging.
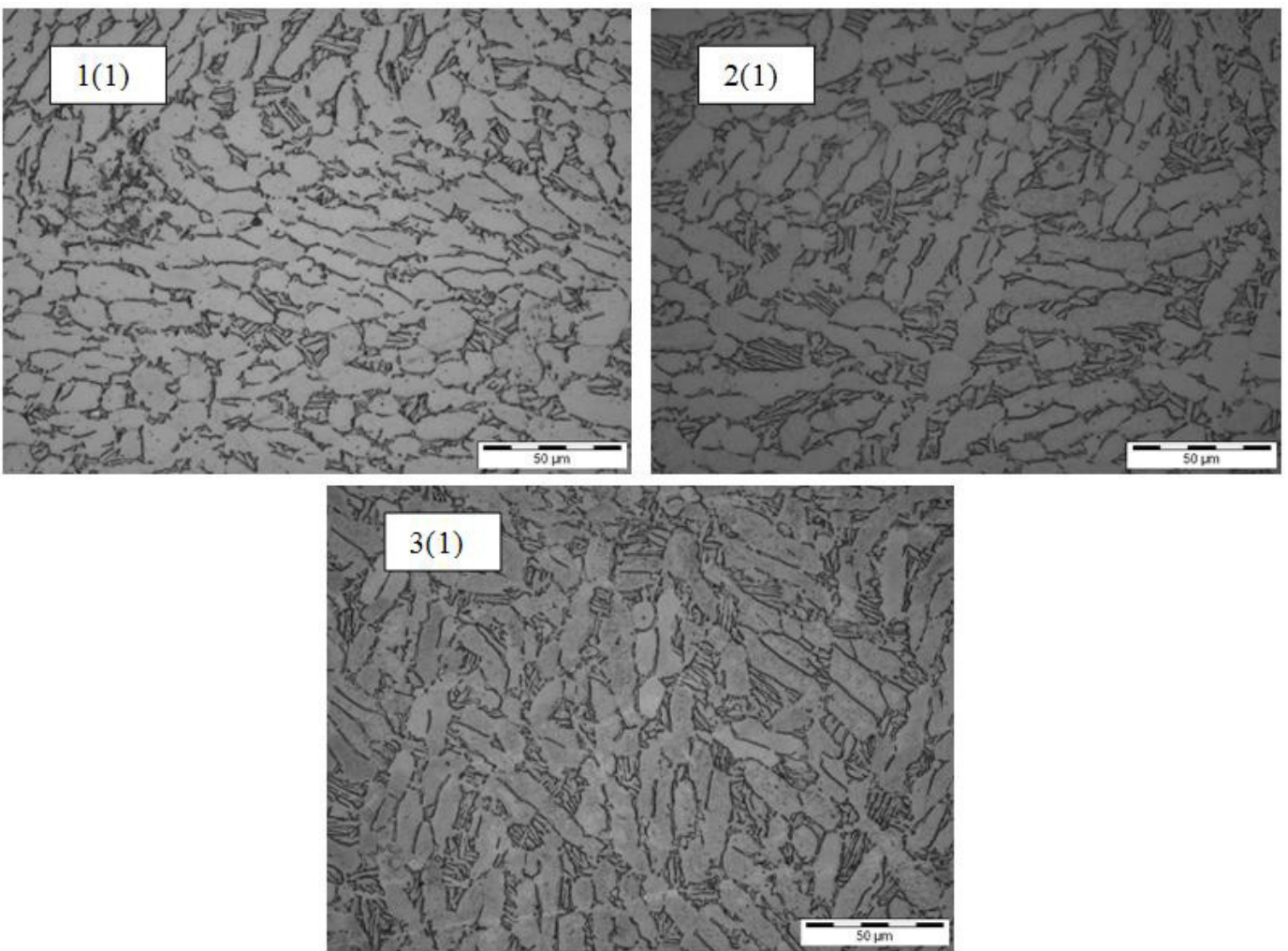

Fig. 42. Microstructure at different positions of hog-out. 


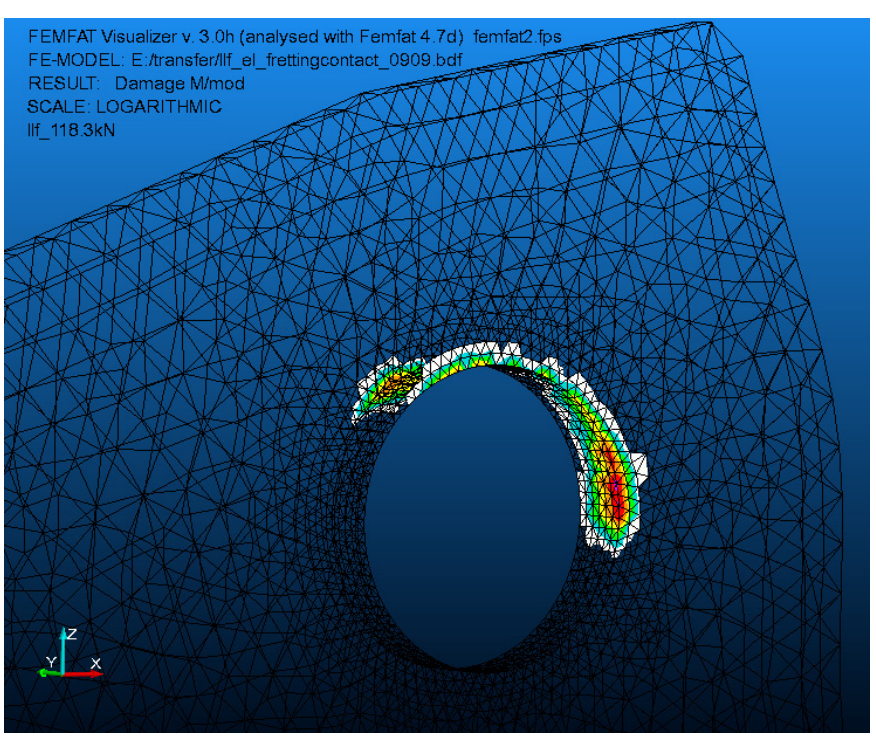

Fig. 43. Femfat simulation of max. load of $118 \mathrm{kN}$.

Acknowledgements. The authors would like to thank the Christian Doppler Research Association, Austria, for financial support.

\section{References}

[1] G. Lütjering, J.C. Williams, Titanium: Engineering materials and processes, Berlin, Springer, 2003

[2] M. Peters, C. Leyens, Titan und titanlegierungen, Weinheim, Wiley, 2002

[3] M. Riedler, M. Stockinger, M. Stoschka, B. Oberwinkler, W. Tan, Linking microstructure and fatigue of forged Ti6Al-4V aerospace parts LCF6, Berlin, 2008, pp. 129-134

[4] M. Stoschka, M. Stockinger, H. Leitner, M. Riedler, Assessment of lifetime calculation of forged IN718 aerospace components based on a multi-parametric microstructural evaluation superalloys, Champion, 2008, pp. $573-582$

[5] B. Oberwinkler, M. Riedler, W. Eichlseder, Importance of residual stresses and surface roughness regarding fatigue of titanium forgings, J. ASTM Int. 7 (2009)

[6] W. Eichlseder, B. Unger, Trends in der Betriebsfestigkeitssimulation, DVM-Conference, 2005

[7] G. Fleischer, 40 Jahre Bewertung von Reibung und Verschleiß mit Hilfe der Energiedichte, Tribologie und Schmierungstechnik, 2004, pp. 5-11 